Math matters during a pandemic: A novel, brief educational intervention combats whole number bias to improve health decision-making and predicts COVID-19 risk perceptions and worry across 10 days

Thompson, C. A. ${ }^{1}$, Taber, J. M. ${ }^{1}$, Sidney, P. G. ${ }^{2}$, Fitzsimmons, C. J. ${ }^{1}$, Mielicki, M. K. ${ }^{1}$, Matthews, P. G. ${ }^{3}$, Schemmel, E. A. ${ }^{1}$, Simonovic, N. ${ }^{1}$, Foust, J. L. ${ }^{1}$, Aurora, P. ${ }^{1}$, Disabato, D. J. ${ }^{1}$, Seah, T. H. S. ${ }^{1}$, \& Coifman, K. G. ${ }^{1}$

\author{
${ }^{1}$ Kent State University \\ ${ }^{2}$ University of Kentucky \\ ${ }^{3}$ University of Wisconsin-Madison
}

This research was supported in part by a U.S. Department of Education Institute of Education Sciences Grant R305A160295 to C. A. Thompson at Kent State University. 


\begin{abstract}
At the onset of the COVID-19 global pandemic, our interdisciplinary team hypothesized that a mathematical misconception--whole number bias (WNB)--contributed to incorrect beliefs that COVID-19 was less fatal than the flu. We created a novel, five-minute online educational intervention, leveraging evidence-based cognitive science research, to encourage accurate COVID-19 and flu fatality rate calculations and comparisons. As predicted, adults $(N=1,297)$ randomly assigned to the intervention were more likely to correctly answer health decision-making problems and were less likely to report WNB errors in their problem-solving strategies relative to control participants. There were no immediate effects of condition on COVID-19 risk perceptions and worry; however, those in the intervention group did exhibit increased perceived risk and worry across 10 days of daily diaries. The intervention did not cause distress; instead, it increased positive affect. Ameliorating WNB errors could impact people's risk perceptions about future health crises.
\end{abstract}




\section{Overview and Significance}

In early 2020, COVID-19 became a global pandemic. The WHO (2020) deemed the outbreak an "infodemic" because of an overabundance of misinformation. Misinformation has likely reduced engagement in adaptive health behaviors across the globe. Interpreting the magnitude of COVID-19 risk--a key predictor of health behavior--requires understanding information presented as rational numbers: fractions, whole number frequencies, and percentages. However, this numerical information is often presented as the total number of deaths across two viruses sans the numbers of confirmed cases, which may lead people to underestimate COVID-19 risk. For example, one popular press article (Netburn, 2020) was titled, The flu has killed far more people than coronavirus. So why all the frenzy about COVID-19?

In the current study, we tested whether an online educational intervention aimed at reducing a mathematical misconception known as whole number bias (WNB) could improve adults' reasoning about COVID-19 risk. WNB occurs when people incorrectly use whole number knowledge to reason about rational numbers (Ni \& Zhou, 2005; Opfer \& DeVries, 2008; Thompson \& Opfer, 2008); for example, thinking about numerators or denominators as whole numbers in isolation rather than parts of a ratio. Reducing WNB errors about COVID-19 risk is critical because accurately interpreting the magnitude, or size, of COVID-19 risk could be one key component to slowing the spread of the virus.

Statistics on COVID-19 infections and deaths are updated minute-by-minute. Early in the pandemic, when COVID-19 deaths were low (Table 1), comparing the number of deaths or the number of people infected with each virus led many to the mistaken conclusion that COVID-19 was less fatal than the flu (a WNB error) (e.g., Faust, 2020; Faust \& Rio, 2020a; Faust \& Rio, 2020b; Rettner, 2020; Walker, 2020; Yan, 2020). However, fatality rates are only comparable 
when deaths are considered relative to the total number infected (fatalityflu_rate $=.06 \%$; fatalitycovID_rate $=4.1 \%$ ). Thus, without these relative comparisons WNB could result in underestimation of risk.

Table 1. COVID-19 and flu statistics as of mid-March 2020 when data were collected

\begin{tabular}{llll}
\hline & $\begin{array}{l}\text { Number of } \\
\text { deaths }\end{array}$ & $\begin{array}{l}\text { Total number of people } \\
\text { infected }\end{array}$ & Case-Fatality Ratio $^{1}$ \\
\hline Flu & 22,000 & $36,000,000$ & $\begin{array}{l}22,000 / 36,000,000=0.00061= \\
.06 \%\end{array}$ \\
COVID-19 & 9,318 & 227,743 & $9,318 / 227,743=0.041=4.1 \%$ \\
\hline
\end{tabular}

\section{Whole Number Bias}

People of all ages and expertise make WNB errors (Alibali \& Sidney, 2015; Braithwaite \& Siegler, 2018; Fazio et al., 2017; Ni \& Zhou, 2005; Obersteiner et al., 2013). WNB occurs across cultures (DeWolf \& Vosniadou, 2015; Gomez et al., 2015; Van Hoof et al., 2020), and is even present in indigeneous peoples (Alonso-Diaz et al., 2019). WNB likely stems from overgeneralizing whole-number knowledge to other numbers, especially ratios (Siegler et al., 2011). Constructs similar to WNB, such as ratio bias and denominator neglect, impair health-related decisions (Lipkus \& Peters, 2009; Nelson et al., 2008; Peters, 2012; Reyna, et al., 2009; Reyna \& Brainerd, 2008).

\footnotetext{
1 Statistics for the flu are U.S. numbers, whereas statistics for COVID-19 are based on global numbers, as reported by the Center for Disease Control and Johns Hopkins websites in mid-March 2020. The numbers presented in Table 1 were used in our study. At the time of data collection, deaths from COVID-19 across the world were much lower than in the ensuing months. Had we chosen to report the U.S.-specific deaths vs. COVID-19 infections, the WNB would have been further exacerbated. Note that though the number of deaths attributed to COVID-19 and the total number of people infected with COVID-19 have both increased substantially since we conducted the current study, fatality rates have remained fairly constant. For instance, on May 19,2020 , the CDC website indicated that the flu fatality rate in the U.S. could be as high as $.11 \%(62,000 / 56,000,000)$ and the COVID-19 case fatality rate in the U.S. was $6.0 \%(91,570 / 1,523,534)$. Information about the pandemic is ever-evolving, as COVID-19 health statistics update daily. Our intervention was developed to help people interpret the dynamic nature of these statistics. In the midst of a pandemic, the total number of people who are infected (the denominator) is unknown, and currently unknowable because of a lack of widespread testing and an unknown number of asymptomatic cases. However, more recent updates suggest that COVID-19 might be 4 times more deadly than the flu (Shabad, 2020).
} 
Reasoning about the magnitude of ratios compared to whole numbers is more effortful, error-prone, and time-consuming (e.g., Fazio et al., 2017; Siegler et al., 2011; Yu et al., in press). According to dual-processing theories, people must first inhibit automatic, over-practiced wholenumber processes before engaging strategic rational number processes (Vamvakoussi, 2015; Vamvakoussi \& Vosniadou, 2010; Vosniadou, 2014). Hence, WNB errors occur when wholenumber processing is not inhibited. With regards to COVID-19, WNB errors result from automatically processing the absolute number of deaths or infections in isolation, rather than strategically processing their relative magnitudes to comprehend fatality rates.

Furthermore, anxiety and negative attitudes associated with COVID-19 could compound WNB by leading people to avoid thinking deeply about numbers. All types of numbers can elicit math anxiety (Ashcraft, 2002; Ashcraft \& Krause, 2007), or apprehension about mathematics (Beilock et al., 2010), and most people report disliking rational numbers more than whole numbers (Sidney et al., 2019).

\section{Educational Interventions Combat Rational Number Misconceptions}

Several evidence-based interventions have improved children's rational number understanding. For example, worked examples providing step-by-step instructions (Renkl, 2014) improve rational number and algebraic outcomes in real classrooms (Star et al., 2016). Breaking non-unit fractions into combinations of unit fractions (e.g., decomposing 2/3 into 1/3+1/3; Braithwaite \& Siegler, 2020) improves fraction understanding. Feedback that helps children use landmarks on a number line (Fazio et al., 2017; Rittle-Johnson et al., 2001) improves estimation precision. Finally, number lines facilitate accurate reasoning about fraction division (Sidney, Thompson, \& Rivera, 2019), and visual models improve learning about density, which is integrally tied to ratio concepts (Schwartz et al., 2011). Although these interventions have improved 
children's rational number understanding, they have not been implemented with adults. Thus, we combined aspects of these interventions to improve adults' understanding of COVID-19 risk.

\section{Risk Perceptions Involve Magnitude Judgments}

Health decision making is impaired when people make mathematical errors (Lipkus \& Peters, 2009; Nelson et al., 2008; Peters, 2012; Reyna \& Brainerd, 2008). Specifically, WNB errors can impede accurately judging one's disease risk or appropriately calibrating disease worry. Risk perceptions--thoughts or feelings about the likelihood of developing a disease, and worry (Chapman et al., 2006; Portnoy et al., 2014)--affective concern about developing a disease--are related yet distinct constructs (Ferrer et al., 2016; Taber et al., 2020) that directly influence health behavior (Brewer et al., 2007; Hay et al., 2006; Sheeran, Harris, \& Epton, 2014).

Risk perceptions and worry involve magnitude judgments, as people consider how big or small their chances of an outcome are. Research on WNB can inform how people judge their risk. Specifically, even if disease rates are equivalent in magnitude, people could be swayed by the size of the whole number components. For example, although $1 / 2$ and $15 / 30$ are equivalent in magnitude (50\%), people overestimate $15 / 30$ on number lines leading to lower precision when estimating 15/30 compared to $1 / 2$ (Braithwaite \& Siegler, 2017; Fitzsimmons et al., in press). With regards to the early COVID-19 death counts, considering the low number of COVID-19 deaths versus the high number of flu deaths may have caused people to underestimate COVID-19 risk. Thus, we expected that an intervention targeting accurate magnitude understanding could influence individuals' risk perceptions and worry. 


\section{Current Study}

We tested whether a novel online educational intervention could reduce adults' tendencies to make WNB errors pertaining to COVID-19 risk, subsequently improving health decision making and increasing risk perceptions over 10 days. The intervention invited calculation of holistic fraction magnitudes (Siegler, 2016; Siegler et al., 2011) instead of considering numerators or denominators in isolation (Opfer \& DeVries, 2008; Thompson \& Opfer, 2008). This brief fiveminute intervention involved evidence-based techniques from laboratory settings to improve rational number understanding (e.g., Fazio et al., 2017; Fitzsimmons et al., in preparation; Fuchs et al., 2016; Schwartz et al., 2011).

Data were collected from March 24-April 9, 2020 from over 1,200 adults across the U.S. The sample was stratified by age, gender, and educational attainment. During data collection, "stay at home" orders due to COVID-19 were beginning across the U.S. The CDC and WHO urged people to treat COVID-19 as a major public health risk. Concurrently, COVID-19 was being compared to the flu in the media, likely inviting WNB errors (Thompson et al., 2020).

Our primary aim was to investigate whether an educational intervention could decrease WNB errors to promote accurate interpretation of COVID-19 health statistics. We hypothesized that (1) WNB errors would be common prior to the intervention, and (2) participants experiencing the intervention, relative to control, would accurately answer post-intervention health decisionmaking problems and commit fewer WNB errors in their reported strategies.

Our secondary aim was to assess the effect of the intervention on risk perceptions, worry, affect, and health behavior. We hypothesized that intervention relative to control participants would report greater perceived risk and worry regarding COVID-19 and explored whether the intervention influenced positive or negative emotional experiences and engagement in 
recommended health behaviors (e.g., social distancing, mask wearing, etc.) across a 10-day followup.

Individual differences might also predict performance on COVID-19 health decisionmaking problems (cf. Thompson et al., invited revision). We used number line estimation precision as a proxy for math skills because performance on this measure is strongly related to overall math achievement (Siegler \& Thompson, 2014; Siegler et al., 2011). We also measured math anxiety because people who struggle with rational number magnitudes exhibit higher math anxiety (Sidney, Thalluri, et al., 2019) and score lower on objective measures of numeracy (Choi et al., 2020), skills crucial to interpreting health risks. We included gender as a covariate because women show lower estimation precision (Hutchison et al., 2019; Rivers et al., under review; Thompson \& Opfer, 2008), and higher levels of math anxiety and negative attitudes about rational numbers than men (Sidney et al., 2019).

Our team consisted of experts in cognitive science, development, math cognition, health and risk perceptions, and affective science. To our knowledge, no other math interventions have taken a daily diary approach to track the longevity of intervention effects. Therefore, we could answer theoretically motivated basic science questions with practical implications for the COVID19 pandemic. COVID-19 is an ecologically valid test case for our theoretical questions, and the intervention should be applicable to other health contexts involving misinterpretation of numeric risks.

\section{Results}

\section{Baseline and Sociodemographic Differences Across Conditions}

We assessed differences across conditions to confirm successful random assignment. There were no condition differences in age, education, employment status, number of math courses taken, 
race/ethnicity, number line estimation PAE, math anxiety, math attitudes, subjective numeracy, objective numeracy, need for cognition, health literacy, or baseline negative or positive affect (all $p \mathrm{~s}>.09)$. There were more males randomly assigned to control $(52.8 \%)$ than to the intervention (47.2\%), $\chi^{2}(1)=4.47, p=.034$. As per our pre-registration analysis plan, we included gender as a covariate in subsequent analyses.

\section{WNB at Baseline}

Baseline health decision-making accuracy was low overall. Only $43.10 \%$ of participants correctly indicated that Disease A was more fatal than Disease B. Another $43.72 \%$ committed WNB by incorrectly selecting the disease with a smaller ratio but larger whole number components. This was a higher rate than random guessing $(33.33 \%$ for three possible responses; $\left.\chi^{2}(1)=56.89, p<.001\right)$. Only $13.18 \%$ of participants incorrectly responded that the diseases were equally fatal.

Consistent with our hypotheses, many participants mentioned WNB errors in their strategy reports (see Appendix F). At baseline, controlling for gender, participants were equally likely to mention WNB errors in their strategy reports across conditions, $b=0.03, p=.805, \mathrm{OR}=1.03,95 \%$ CI $[0.81,1.32]$. Notably, those who responded incorrectly were far more likely to report a WNB error in their baseline strategy reports than those who answered correctly $(47.6 \%$ vs. $2.5 \%)$, $\chi^{2}(1)=317.09, p<.001$

\section{Immediate Effect of the Intervention on Health Decision-Making Accuracy}

We conducted logistic regressions, controlling for gender, to examine the effect of the educational intervention on health decision-making accuracy. As hypothesized, participants in the intervention condition were more likely than those in the control to correctly answer that COVID19 is more fatal than the flu $(b=1.31, p<.001, \mathrm{OR}=3.71,95 \% \mathrm{CI}[2.85,4.85])$. Observed frequencies 
indicated that more individuals answered correctly in the intervention (42.41\%) compared to the control condition (29.68\%). One of the two possible incorrect responses was consistent with WNB. Of the $27.91 \%$ who were incorrect across conditions, $67.13 \%$ of those individuals chose the response consistent with WNB (flu was more fatal than COVID-19) compared to the incorrect response that did not involve WNB (they were equally fatal; $32.87 \%$ ), $\chi^{2}(1)=42.48, p<.001$. Thus, WNB led to incorrect responses. Males were more likely than females to respond correctly (observed frequencies of those who answered correctly: $M_{M}=77.4 \%, M_{F}=67.6 \%$ ), $b=0.62, p<.001$, $\mathrm{OR}=1.85,95 \% \mathrm{CI}[1.43,2.41]$. Even after controlling for additional covariates typically associated with accuracy on math tasks (Appendix Table A1), participants in the intervention condition were more likely to answer correctly relative to control, $b=1.42, p<.0001$, OR=4.14, 95\% CI [3.11,5.57].

Next, we analyzed responses to the near and far transfer problems. Across conditions, more participants who incorrectly answered the two transfer problems selected the WNB response than the other incorrect response (near transfer: $77.66 \%$ vs. $22.34 \%, \chi^{2}(1)=293.22, p<.001$; far transfer; $73.27 \%$ vs. $\left.26.73 \%, \chi^{2}(1)=112.62, p<.001\right)$. Participants were more likely to correctly answer the near transfer problem in the intervention than in the control condition (Appendix Table A2), when controlling for gender, $b=0.35, p=.007, \mathrm{OR}=1.41,95 \% \mathrm{CI}[1.10,1.82]$, or the larger set of covariates, $b=0.40, p=.006, \mathrm{OR}=1.48,95 \% \mathrm{CI}[1.12,1.98]$. Simple frequencies indicated that more individuals within the intervention condition answered correctly $(29.01 \%)$ compared to the control (23.21\%). Contrary to hypotheses, there were no condition differences on the far transfer problem when controlling for gender, $b=-0.04, p=.747, \mathrm{OR}=0.96,95 \% \mathrm{CI}[0.77,1.21]$, or the larger set of covariates, $b=-0.09, p=.486, \mathrm{OR}=0.91,95 \% \mathrm{CI}[0.71,1.18]$ (Appendix Table A3).

We tested the interaction between magnitude knowledge (PAE) and condition because people may benefit more from the educational intervention if they began the experiment with lower 
mathematical skills, thus had more "room to grow." However, this interaction was not significant, did not improve model fit, and is not discussed further.

\section{WNB in Strategy Reports}

Across conditions, the proportion of people who reported WNB strategies was greater among those who answered the health decision-making problems incorrectly compared to correctly: immediate posttest, $\chi^{2}(1)=187.78, p<.001$ (observed frequencies: $35.91 \%$ for incorrect vs. $5.99 \%$ for correct); near transfer, $\chi^{2}(1)=96.55, p<.001$ (observed frequencies: $27.97 \%$ for incorrect vs. $2.36 \%$ for correct $)$; far transfer, $\chi^{2}(1)=63.74, p<.001(31.73 \%$ for incorrect vs. $13.26 \%$ for correct).

We conducted parallel logistic regressions predicting WNB strategy use on the posttest problems. As hypothesized, participants were less likely to report WNB errors at immediate posttest in the intervention than in the control condition (observed frequencies: intervention $=18.69 \%$ vs. control $=10.08 \%$ ), both when controlling for gender, $b=-0.74, p<.001$, $\mathrm{OR}=0.48,95 \% \mathrm{CI}[0.34,0.66]$, and the larger set of covariates, $b=-0.90, p<.001, \mathrm{OR}=0.41,95 \%$ CI $[0.28,0.59]$. In the simplified model, females were more likely than males to report a WNB error, $b=-0.33, p=.042, \mathrm{OR}=0.72,95 \% \mathrm{CI}[0.52,0.99]$. In the model including the full set of covariates, those who reported a WNB error at baseline relative to those who did not, younger participants, those with higher PAE, or those with higher math anxiety were more likely to report a WNB error (Appendix Table A4).

For near transfer (Appendix Table A5), participants were less likely to report WNB errors in the intervention than in the control condition (observed frequencies: intervention: 19.24\% vs. control: $23.36 \%$ ), both when controlling for gender, $b=-0.29, p=.033, \mathrm{OR}=0.75,95 \% \mathrm{CI}$ $[0.57,0.98]$, and additional covariates, $b=-0.40, p=.011, \mathrm{OR}=0.67,95 \% \mathrm{CI}[0.49,0.91]$. Similar to 
the immediate posttest, the likelihood of reporting WNB errors was greater for females relative to males (in both the simplified model, $b=-0.72, p<.001, \mathrm{OR}=0.49,95 \% \mathrm{CI}[0.37,0.65]$, and the model including the full set of covariates, $b=-0.56, p=.001$, OR=0.57, 95\% CI $[0.40,0.80])$, for those who reported a WNB error at baseline relative to those who did not, for younger participants, or those with higher PAE (Appendix Table A5).

For far transfer (Appendix Tables A6), there was no effect of condition (control $=51.49 \%$ vs. intervention $=48.51 \%$ ) when controlling for gender, $b=-0.11, p=.411, \mathrm{OR}=0.89,95 \% \mathrm{CI}$ $[0.68,1.17]$, or other covariates, $b=-0.13, p=.380, \mathrm{OR}=0.88,95 \%$ CI $[0.66,1.17]$. Those who reported a WNB error at baseline relative to those who did not, younger participants, those with a high-school education or less relative to those who have completed some college or held an associate's degree, those with higher PAE, higher math anxiety, or less positive math attitudes were more likely to report a WNB error on the far transfer problem.

\section{Immediate Effect of the Intervention on Risk Perceptions, Worry, and Affect}

Next, we examined the immediate effect of the intervention on participants' COVID-19 risk perceptions and worry, controlling for gender (see Appendix Tables A7 and A8). Contrary to hypotheses, neither risk perceptions, $b=-0.02, t(1083)=-0.31, p=.759$ nor worry, $b=0.06$, $t(1271)=1.27, p=.204$, differed across conditions.

We examined the immediate effect of the intervention on negative and positive affect, controlling for gender (see Appendix Tables A9 and A10). Negative affect did not differ by condition, $b=-0.03, t(1287)=-0.38, p=.703$, or gender, $b=0.01, t(1287)=0.14, p=.892$. However, participants reported greater positive affect in the intervention relative to the control condition, $b=0.21, t(1287)=2.82, p=.005$, and males reported greater positive affect than females, $b=0.27$, 
$t(1287)=3.57, p<.001$. Thus, the intervention did not cause immediate distress but did increase positive affect.

\section{Long-term Effect of the Intervention on Daily Risk Perceptions, Worry, Affect, and Behavior}

Next, we examined the long-term effects of the intervention on participants' COVID-19 risk perceptions, worry, positive and negative affect, and reports of recommended health behaviors in daily diaries completed in the 10 days following the intervention.

Risk perceptions and worry. Initial analyses examined the effect of condition on risk perceptions (Appendix Table B1) and worry (Appendix Table B2) over time, with day as a fixed factor at Level 1 and condition and gender as fixed factors at Level 2. Participants in the intervention relative to the control condition reported increases in risk perceptions, $\mathrm{B}=0.24$, $\mathrm{SE}=0.18, p=0.173$ and worry across 10 days, $\mathrm{B}=0.23, \mathrm{SE}=0.14, p=.093$, though these effects did not reach statistical significance. Males had significantly higher worry than females, $\mathrm{B}=0.28$, $\mathrm{SE}=0.14, p=0.041$. Notably, risk perceptions increased with each increasing day, $\mathrm{B}=0.05$, $\mathrm{SE}=0.01, p<.001$. Worry, however, did not increase over 10 days, $\mathrm{B}=0.001, \mathrm{SE}=0.006, p=.876$.

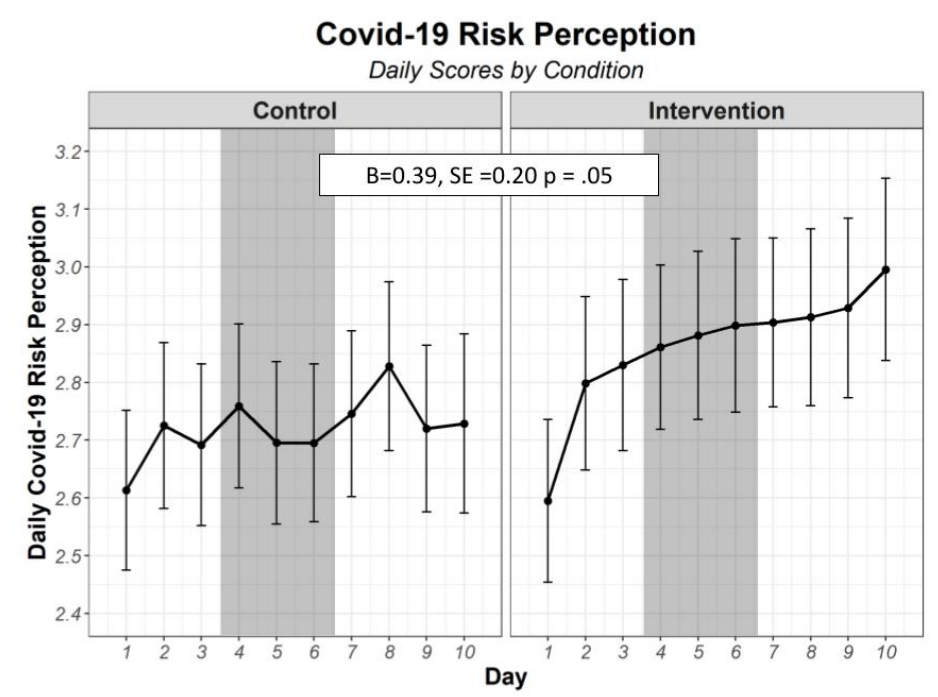

Figure 1. Ratings of COVID-19 risk are greater for the intervention condition on days 4, 5, and 6 of longitudinal sampling relative to the control condition. 
Separate plots of risk perceptions and worry by condition indicated non-linear change of perceived risk and worry across 10 days, thus in follow-up analyses, we examined the initial (days 1-3), middle (days 4-6) and final (days 7-10) periods of the diary assessment. Individuals in the intervention relative to the control condition reported greater perceived risk during the middle period, $\mathrm{B}=0.39, \mathrm{SE}=0.20, p=.051$ (see Figure 1). However, perceived risk in the initial period, $\mathrm{B}=0.15, \mathrm{SE}=0.19, p=.43$, and final period, $\mathrm{B}=0.31, \mathrm{SE}=0.21, p=.14$, did not differ by condition. For worry, individuals in the intervention relative to the control condition reported significantly greater worry in the initial period, $\mathrm{B}=0.43, \mathrm{SE}=0.18, p=.017$. Further, day moderated the effect of condition, such that worry increased across days within the initial period for participants in the intervention, but worry declined over the initial period for participants in the control condition, $\mathrm{B}=-0.10, \mathrm{SE}=0.05, p=.053$. After the initial period, individuals in the intervention relative to the control condition maintained greater worry, though the effect was not significant in the final period, $\mathrm{B}=0.25, \mathrm{SE}=0.15, p=.09$ (see Figure 2).

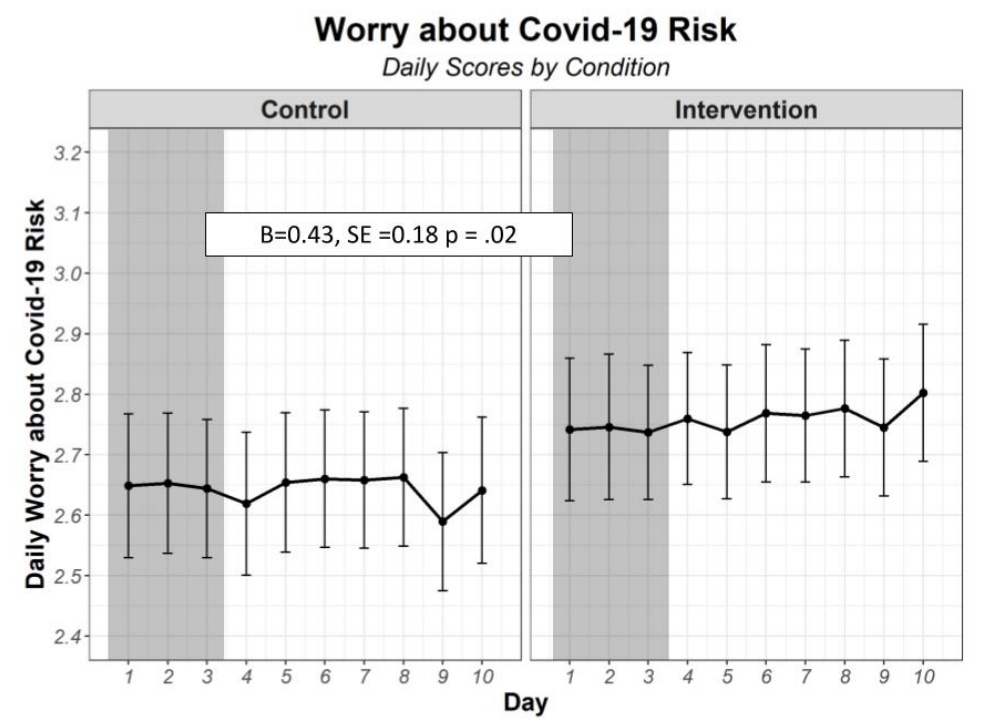


Figure 2. Ratings of COVID-19 worry are greater for the intervention condition on days 1, 2, and 3 of longitudinal sampling relative to the control condition.

Positive and negative affect. We then examined the impact of the intervention on reported negative (Appendix Table B3) and positive affect (Appendix Table B4) over 10 days, with day at Level 1 and condition and gender at Level 2. Results suggested individuals in the intervention relative to the control condition reported higher, albeit non-significant, levels of positive affect across 10 days, $\mathrm{B}=0.095, \mathrm{SE}=0.063, p=0.13$. However, there was a negative association with time, as reports of positive affect decreased slightly with each increasing day for all participants, $B=-$ $0.02, \mathrm{SE}=0.00, p<.001$. In addition, males reported greater positive affect than females, $\mathrm{B}=0.18$, $\mathrm{SE}=0.06, p=0.006$. In contrast, there was no impact of condition or gender on negative affect; although negative affect decreased with passing days for all participants, $\mathrm{B}=-0.01, \mathrm{SE}=0.00$, $p=0.07$.

Follow-up analyses examined positive affect across the initial, middle, and final periods of the diary assessment. The difference in positive affect across conditions was greatest in the initial period, $\mathrm{B}=0.12, \mathrm{SE}=0.07, p=0.06$, and dissipated over time (see Figure 3 ). We did not further examine negative affect because it did not vary by condition. 


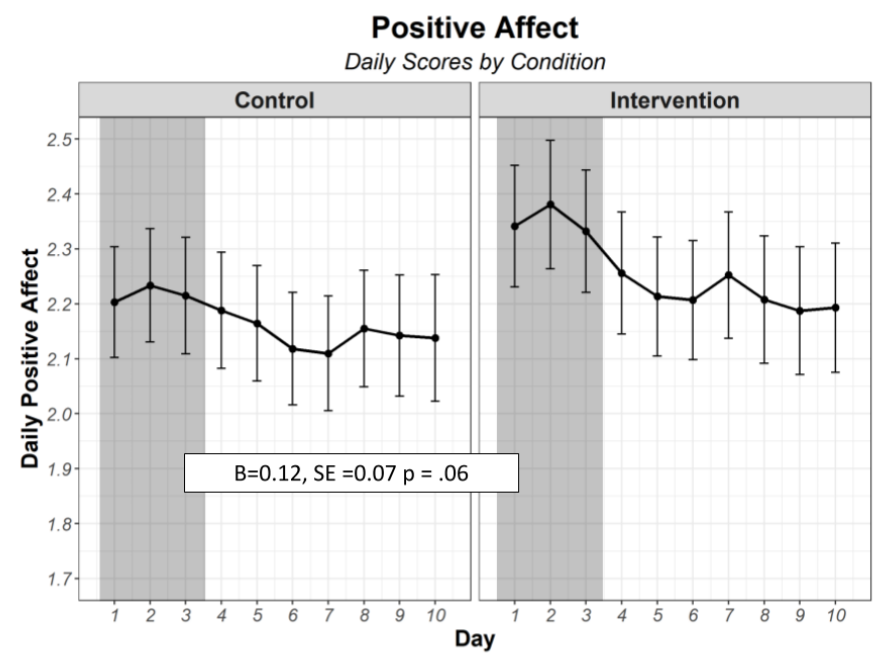

Figure 3. Ratings of positive affect are greater for the intervention condition on days 1, 2 and 3 of longitudinal sampling relative to the control condition.

Engagement in preventive health behaviors. Finally, we examined the association between the intervention and recommended preventive health behaviors (per the U.S. CDC) reported over 10 days. As expected, affect was significantly associated with behaviors, such that greater positive and negative state and trait affect predicted greater daily use of recommended behaviors (see Appendix Table B5). There was no effect of condition on behaviors both when including affect in the model, $\mathrm{B}=0.15, \mathrm{SE}=0.15, p=.34$, and when gender and condition were the only predictors in the model, $\mathrm{B}=.20, \mathrm{SE}=.17, p=.23$. There was a relatively small but inverse association between time and behaviors: the probability of endorsing one recommended health behavior decreased by $6 \%$ with each additional day: $\mathrm{B}=-0.06, \mathrm{SE}=0.01, p<.001$.

Robustness checks. Finally, we controlled for significant math predictors of health decision-making (i.e., PAE, baseline health decision-making accuracy, and math anxiety) along with demographic factors (i.e., gender, age, educational attainment, and race). Including this larger set of covariates did not change the effects of condition on daily diary outcomes (i.e., risk perceptions, worry, affect, or health behaviors) (see Appendix B). Model fit statistics for the daily 
diary analyses indicated only minor improvements with additional covariates (e.g., AIC/BIC/AICC decreased by 6-12), suggesting that benefits of considering these additional covariates in the daily diary models were negligible except when positive and negative affect were the dependent variables. In those cases, the addition of socio-demographic and math covariates did enhance model fit (e.g., AIC/BIC/AICC decreased by 50-90). Of note, math anxiety was a significant positive predictor of risk perceptions, worry, and negative affect immediately postintervention and across 10 days (refer to Appendix A and B).

\section{Discussion}

This online experiment, with over 1,200 adult participants from a nationally representative U.S. sample, was conducted near the onset of the COVID-19 pandemic, when misinformation was widespread (Thompson et al., 2020). Our educational intervention, designed to combat WNB errors, facilitated higher post-intervention health decision-making accuracy and transfer, relative to control. Aligned with prior research (Thompson et al., invited revision), health decision-making accuracy and strategy reports in the current study provided convergent evidence for WNB. The intervention led to fewer reported WNB errors even after controlling for gender, WNB errors at baseline, math anxiety, math skills, and age. For health decision-making questions in multiplechoice format (e.g., Cuite et al., 2008; Waters et al., 2007), people can guess correctly a substantial portion of the time (33.33\% in the current study). Further, specific numerators and denominators chosen for health decision-making problems can impact prevalence of WNB (Bonato et al., 2007; Fazio et al., 2017; Sidney, Thalluri, et al., 2018; Schneider \& Siegler, 2010). One advantage of collecting both accuracy and strategy reports for health decision-making problems is that this multi-pronged approach affords insight into why participants answered correctly or incorrectly, thus highlighting WNB errors. 
We also identified individual differences that contributed to health decision-making outcomes. Math skills and gender predicted post-intervention health decision-making accuracy and transfer. Males were more likely than females to correctly answer the baseline health decisionmaking problem $(\mathrm{OR}=1.98,95 \%$ CI $[1.59,2.48])$. Research suggests men produce more precise number line estimates than women (Hutchins et al., 2019; Rivers et al., under review; Thompson \& Opfer, 2008), which may give men an advantage when considering numerical magnitudes in health decision-making contexts. Future research can determine whether these differences result from differences in spatial ability (Newcombe et al., 2019; Rivers et al., under review) or formal/informal learning experiences (Halpern et al., 2007; Levine et al., 2010; Pruden et al., 2011). Also, adults with greater math anxiety were less accurate on the near transfer problem and reported greater risk perceptions, worry, and negative affect. Therefore, the role of math anxiety in health risk perceptions and worry should be further explored.

Our finding that $44 \%$ of adults showed WNB errors at baseline may underestimate WNB prevalence (though Waters et al., 2007 report a similar rate). After applying pre-registered exclusion criteria, $51 \%$ of participants who were incorrect vs. $37 \%$ of participants who were correct on the baseline health decision-making problem were excluded. Because the study was conducted online, we cannot determine whether excluded participants had low math skills, exhibited low effort, or were bots. Adults who might benefit most from the intervention may have dropped out or were considered poor responders.

Another novel contribution of this experiment is that it tested the impact of a mathematical intervention on risk perceptions and worry related to COVID-19, as well as affect and engagement in recommended health behaviors. Although condition did not predict COVID-19 risk perceptions or worry immediately post-intervention in the baseline session, intervention participants later 
reported increased risk perceptions and worry relative to control participants in the daily diaries. Specifically, increases in COVID-19 worry during Days 1-3 were somewhat maintained over time, and COVID-19 risk perceptions increased for intervention participants beginning on Day 4 of diaries. Even though the intervention increased risk perceptions and worry, it increased positive affect over several days and did not cause distress. Exploratory analyses indicated the intervention did not increase adults' engagement in recommended health behaviors. However, behavior change was not the intervention target. Health behaviors are driven by numerous factors, including but not limited to, habits, emotion, socioeconomic status, health literacy, and health cognitions (Glanz \& Bishop, 2010; Michie et al., 2011; Stokols, 1996).

Although many factors contribute to health decision making, our findings underscore the necessity of robust rational number skills for understanding health statistics. Future work in health decision making should measure rational number estimation precision, not just whole number estimation (e.g., Peters \& Bjalkebring, 2015), as a proxy for general math skills (Fazio et al., 2014; Siegler \& Thompson, 2014; Siegler et al., 2011). Given that the Berlin Numeracy measure is commonly used as a measure of math skills in the health decision-making literature, and it relies primarily on whole number knowledge (Cokely et al., 2012), we explored whether rational number estimation precision (PAE) improved model fit for correctly answering the health decision-making problems. Adding PAE to models with condition, gender, and numeracy improved model fit for all health problems $\left(\chi^{2}(1) \mathrm{s}>56, p \mathrm{~s}<.001\right)$, suggesting that rational number skills should be considered in future health decision-making research. Assessing number line estimation skills is fast (Fazio et al., 2017), and these tasks are easy to administer online (e.g., with Qualtrics sliders) or on paper. ${ }^{2}$

\footnotetext{
${ }^{2}$ Researchers interested in assessing WNB should consult Braithwaite and Siegler (2018) and Fitzsimmons et al. (in press). Detailed discussions of estimation precision calculations (PAE) can be found in Siegler et al. (2011).
} 
Our findings have theoretical implications for research on math cognition, health decisionmaking, and risk perceptions. The evidence-based math intervention included analogies, worked examples, preparatory activities, and number line visualizations to improve adults' health decision-making accuracy during an emerging health crisis. Drawing analogies between similar relationships in disparate contexts is "what makes us smart" as a species (Gentner, 1983; 2003). The current intervention effectively leveraged people's spontaneous tendency to engage with comparisons by fostering analogies between familiar (rotting apples in two different orchards) and unfamiliar (disease fatality rates) contexts, contributing to a growing literature on using analogies to understand health risk (Bostrom, 2008; Galesic \& Garcia-Retamero, 2012). However, the penchant for analogical reasoning may also lead humans to compare COVID-19 to other illnesses, like the flu, with inherent error. Growing COVID-19 death counts have fueled new analogies in the media (e.g., risks associated with skydiving, giving birth, and being a soldier during wartimes; Roberts, 2020) that all may be impacted by WNB.

Strikingly, knowledge from the intervention transferred to untrained problems. This is promising given that transfer is often elusive (Barnett \& Ceci, 2002; Kaminski et al., 2008; Klahr \& Chen, 2011). Far transfer could be attainable if the intervention was administered at a higher dosage distributed across time (Dunlosky et al., 2013). Future research should dismantle and identify the most effective ingredient of the intervention and determine the longevity of the intervention beyond 10 days. Assessing math intervention efficacy across extended periods is uncommon because maturational influences or other formal/informal educational experiences could impact post-intervention performance (though see Ramani \& Siegler [2009]). Another open question is how adults' risk perceptions change across time as they process up-to-the-moment COVID-19 information. 
In addition to reducing WNB, the intervention led to increases in perceived risk of COVID19 during a 10-day diary assessment. This is meaningful because risk perceptions are difficult to change, especially when people underestimate their risk (Weinstein \& Klein, 1995). For example, increased risk perceptions are often not sustained among individuals who test positive for a genetic mutation conferring increased objective risk (Aspinwall et al., 2014; Braithwaite et al., 2004; Heshka et al., 2008). Here, we attempted to increase perceived COVID-19 risk and worry, given misleading media reports that COVID-19 was less fatal than the flu. The educational intervention likely changed risk perceptions because they inherently involve an approximate assessment of magnitude (e.g., low vs. high risk), and the effects appeared to last for days. Notably, individuals' personalized COVID-19 risk was unknowable, so accuracy of perceived risks could not be assessed at this time. However, as more definitive information about COVID-19 risk factors are uncovered, alignment between perceived and objective risk can be determined. Perceived risks and worry for oneself and others were strongly correlated; relatively few prior studies have examined risk perceptions for close others (see Ghassemi et al., 2020; Klein \& Ferrer, 2018), despite calls for greater attention to interpersonal processes (Rothman et al., 2020). This is particularly relevant in a highly contagious pandemic context when one's health behaviors affect others (i.e., hand washing or vaccination).

Our findings have practical education and health implications. The intervention showed promise to address a major mathematical and health misconception with potentially fatal consequences: the flu is more fatal than COVID-19. It marks a step toward translational, benchto-bedside research (Booth et al., 2017) by harnessing cognitive science to inform COVID-19 health communication. This intervention could be widely disseminated to decrease WNB errors in other real-life contexts (e.g., converting salary to hourly pay, considering infection rates and side 
effect rates of drugs, etc.). Given the far-reaching effects of this brief intervention, which decreased WNB errors, it is imperative to refine additional interventions to mitigate other mathematical misconceptions (e.g., Furlong \& Opfer, 2009).

In summary, our short educational intervention about COVID-19 case fatality rates diminished WNB errors--a prevalent mathematical misconception experienced by all people. This is the first study, to our knowledge, in which the detrimental impact of WNB errors was assessed during a real-world health pandemic. Our findings are robust because condition differences held even when we controlled for a range of demographic and math factors. This intervention has the potential to make a large, positive impact on health cognitions during the COVID-19 public health crisis. Health officials and the media often express risk information numerically, and novel health threats will continue to emerge. Thus, it is critical to examine how people engage with numeric information and experience WNB in other unexpected and unprecedented health contexts. 


\section{Method}

\section{Participants}

Table 2. Participant characteristics.

\section{N Percent}

\section{Race and Ethnicity}

White

$96974.71 \%$

Black or African American

$134 \quad 10.33 \%$

American Indian or Alaska Native

$8 \quad 0.62 \%$

Asian

$50 \quad 3.86 \%$

Native Hawaiian or Pacific Islander

$3 \quad 0.23 \%$

Hispanic or Latino

$51 \quad 3.93 \%$

Other

$13 \quad 1.00 \%$

Did not report

$3 \quad 0.23 \%$

Multiple

$66 \quad 5.09 \%$

\section{Employment}

\begin{tabular}{lrr}
\hline Employed for wages & 536 & $41.33 \%$ \\
Self-Employed & 112 & $8.64 \%$ \\
Out of work $>$ 1 year & 77 & $5.94 \%$ \\
Out of work $<$ 1 year & 55 & $4.24 \%$ \\
Homemaker & 91 & $7.02 \%$ \\
Student & 96 & $7.40 \%$ \\
Retired & 315 & $24.29 \%$ \\
Rather not report & 15 & $1.16 \%$
\end{tabular}

Gender

\begin{tabular}{lrc}
\hline Male & 593 & $45.72 \%$ \\
Women & 697 & $53.74 \%$ \\
Other gender & 2 & $<0.01 \%$ \\
Rather not report & 5 & $<0.01 \%$
\end{tabular}

Education

$\begin{array}{lll}<\text { High School \& High School } \quad 389 & 29.99 \%\end{array}$




\begin{tabular}{lrr} 
Some College or Associates & 472 & $36.39 \%$ \\
Bachelor's & 285 & $21.97 \%$ \\
Graduate degree & 151 & $11.64 \%$ \\
Income & & \\
\hline$<15,000$ & 155 & $11.95 \%$ \\
$15,000-24,999$ & 147 & $11.33 \%$ \\
$25,000-34,999$ & 146 & $11.26 \%$ \\
$35,000-49,999$ & 190 & $14.65 \%$ \\
$50,000-74,999$ & 252 & $19.43 \%$ \\
$75,000-99,999$ & 154 & $11.87 \%$ \\
$100,000-149,999$ & 140 & $10.79 \%$ \\
$150,000-199,999$ & 41 & $3.16 \%$ \\
$>200,000$ & 33 & $2.54 \%$ \\
Would rather not report & 39 & $3.01 \%$ \\
\hline & $M$ & \\
Math Courses Taken & $(\mathrm{SD})$ & Range \\
\hline & 3.84 & \\
Sum of Math Courses (max of 11) & $(2.59)$ & $0-11$ \\
\hline
\end{tabular}

Note: For the purpose of analyses, males were coded as 1, and participants who selected "female," "other," or chose not to answer were coded as 0 . For ease of interpretation we refer to the latter group as "women" although we acknowledge this is an inaccurate category label.

In our $\quad$ pre-registration (https://osf.io/fthm3/?view_only=dc93269c950945be8cf3b07ca9030a8b), we planned to sample 1,200 people and collect data from at least 625 . This stopping rule was based on the availability of funds to collect the data through Qualtrics. Data were collected from March 24 to April 9, 2020 through Qualtrics panels. We sought to recruit equivalent numbers of males and females and to stratify by educational attainment to represent education levels in the U.S. population (although in the final sample, a smaller proportion of people (3.9\%) had earned less than a high school diploma than in the overall U.S. population (12.3\%, U.S. Census Quick Facts). Seventy-five percent of participants self-identified as White, $46 \%$ identified as male, $41 \%$ reported being employed for 
wages, and $70 \%$ reported having between some college experience and a graduate degree. See Table 2 for demographics.

We embedded checks on attention and engagement during the baseline assessment and over the 10 days of daily diaries, per recommendations (Behrend et al., 2011; Hauser \& Schwarz, 2016; Meyerson \& Tryon, 2003). Data cleaning processes, detailed in the Appendix D, reduced the sample from an initial 2,693 adults who consented to 1,297 who provided adequate data and compliance. There were some differences between those included and those excluded from analysis: those excluded were younger and more likely to be white, female, students, or selfemployed. They were also less likely to be retired or employed for wages, report lower income, have taken fewer math courses, and be incorrect on the objective numeracy and baseline health decision-making question. The analytic sample including daily diary data was reduced further because only 709 participants completed at least some of the daily diaries, and other participants were excluded based on compliance or failure to respond to attention checks within the diaries (see Appendix D). The final diary sample was 627 individuals who completed $75 \%(4,703 / 6,270=0.75)$ of the possible diary signals $(M=7.58, S D=3.11)$.

\section{Experimental Design and Procedure}

A flowchart of the study procedures can be found in Appendix C. On Day 1, participants completed a 40-minute online study consisting of a baseline survey, randomly assigned intervention condition, and an immediate posttest. The baseline survey assessed (1) sociodemographic factors, (2), perceived knowledge of COVID-19 and positive and negative affect, and (3) math tasks known to predict WNB. Then, participants were randomly assigned to one of two conditions. In the educational intervention condition, participants completed an intervention that taught them how to calculate a case fatality rate. In the business-as-usual control 
condition, participants saw relevant statistics (i.e., number of deaths; number of infected individuals), but were not shown how to calculate case fatality rates. After the intervention, participants completed three problems assessing health decision-making accuracy and reported the strategy they used to solve each problem (see Table 3 and Appendix E). Additional dependent variables assessed after the intervention were health cognitions about COVID-19 and positive and negative affect. Participants also completed two individual difference measures at the end of the baseline session: need for cognition and health literacy. For the next 10 days, participants completed experience sampling one time each evening to track the impact of the educational intervention on their risk perceptions, worry, positive and negative affect, and preventive health behaviors. 
Table 3. Measures of health decision making

Baseline
\begin{tabular}{|l|l|l|}
\hline $\begin{array}{l}\text { Total \# } \\
\text { deaths }\end{array}$ & $\begin{array}{l}\text { Total \# } \\
\text { infected }\end{array}$ \\
\hline A & 2,125 & 55,924 \\
\hline B & 16,777 & $1,677,720$ \\
\hline
\end{tabular}

Which disease is more fatal: Disease A, Disease B, or are they equally fatal?

Please describe in as much detail as possible how you made your decision about which disease is more fatal.
Post Intervention

\begin{tabular}{|l|l|l|}
\hline & $\begin{array}{l}\text { Total \# } \\
\text { deaths }\end{array}$ & $\begin{array}{l}\text { Total \# } \\
\text { infected }\end{array}$ \\
\hline Flu & 22,000 & $36,000,000$ \\
\hline $\begin{array}{l}\text { COVID- } \\
19\end{array}$ & 9,318 & 227,743 \\
\hline
\end{tabular}

Which disease is more fatal: the flu, COVID-19, or are they equally fatal?

Please describe in as much detail as possible how you made your decision about which disease is more fatal.
Near Transfer

\begin{tabular}{|l|l|l|}
\hline & $\begin{array}{l}\text { Total \# } \\
\text { deaths }\end{array}$ & $\begin{array}{l}\text { Total \# } \\
\text { infected }\end{array}$ \\
\hline $\begin{array}{l}\text { Jan. } \\
30\end{array}$ & 170 & 7,818 \\
\hline $\begin{array}{l}\text { Feb. } \\
6\end{array}$ & 565 & 28,276 \\
\hline
\end{tabular}

Did the COVID-19 fatality rate: increase, decrease, or stay the same from January 30 th to February 6th?

Please describe in as much detail as possible how you made your decision about the possible change in fatality rates.
Far Transfer

According to the WHO

Situation Report, 81,174

people have been infected by COVID-19 in China, whereas 35,713 people have been infected by COVID-19 in Italy.

According to the UN, China has a total population of $1,439,323,774$, and Italy has a total population of $60,461,828$.

Does China have a higher, lower, or the same infection rate as Italy?

Please describe in as much detail as possible how you made your decision about the number of people who have been infected.

Note: All health decision-making problems were forced choice. We have bolded the correct responses here for readers. All strategy reports were open-ended.

\section{Materials}

Measures are described in the order administered. Reliability, means, and standard deviations for all measures, and correlations among measures, are reported in Table 4.

\section{Sociodemographic Factors}

Prior to giving informed consent, participants indicated eligibility by confirming they were $18+$ years of age and held U.S. citizenship. After providing informed consent, participants answered demographic questions including: age, gender, employment status, level of educational 
attainment, number and type of math courses taken in high school and college, the type of device they used to complete the survey, race/ethnicity, household income, and zip code (the latter of which was beyond the scope of this paper). Responses of "Would rather not report" for the employment variable were coded as missing. Race was coded as white vs. non-white for statistical analyses.

\section{Baseline Health Decision Making Problem}

Participants determined which of two hypothetical diseases was more fatal in the baseline health decision-making problem. Disease A included a bigger numerator and a bigger denominator (analogous to flu statistics); Disease B included a smaller numerator and a smaller denominator (analogous to COVID-19 statistics; see Table 3 for the full problem). The numbers chosen in the baseline problem for Disease A were proportional to the numbers for the flu and the numbers for Disease B were proportional to COVID-19 numbers as of March 24, 2020 when the survey launched. 
Table 4. Descriptive statistics and correlations for measures in survey.

\begin{tabular}{|c|c|c|c|c|c|c|c|c|c|c|c|c|c|c|c|c|c|c|c|}
\hline & 1 & 2 & 3 & 4 & 5 & 6 & 7 & 8 & 9 & 10 & 11 & 12 & 13 & 14 & 15 & 16 & 17 & 18 & 19 \\
\hline \multicolumn{20}{|l|}{ 1. Percent Absolute Error } \\
\hline 2. Need for cognition & -0.17 & & & & & & & & & & & & & & & & & & \\
\hline 3. Math Anxiety & $\mathbf{0 . 3 7}$ & -0.20 & & & & & & & & & & & & & & & & & \\
\hline 4. Math Attitudes & -0.34 & 0.44 & -0.35 & & & & & & & & & & & & & & & & \\
\hline 5. COVID Knowledge & 0.01 & 0.14 & 0.01 & 0.19 & & & & & & & & & & & & & & & \\
\hline 6. Health Literacy & -0.18 & 0.14 & -0.28 & 0.01 & 0.08 & & & & & & & & & & & & & & \\
\hline 7. Baseline Risk Perceptions & -0.06 & -0.02 & 0.15 & 0.05 & 0.10 & -0.11 & & & & & & & & & & & & & \\
\hline 8. Baseline Perceived Worry & $\mathbf{0 . 0 7}$ & -0.02 & 0.25 & 0.05 & 0.16 & -0.17 & 0.59 & & & & & & & & & & & & \\
\hline 9. Perceived Severity & 0.04 & 0.03 & 0.06 & -0.02 & 0.12 & 0.10 & 0.24 & 0.36 & & & & & & & & & & & \\
\hline 10. Pretest Positive Affect & 0.14 & 0.10 & 0.03 & 0.17 & 0.10 & -0.18 & -0.06 & -0.13 & -0.10 & & & & & & & & & & \\
\hline 11. Pretest Negative Affect & $\mathbf{0 . 0 7}$ & -0.05 & 0.32 & 0.07 & 0.09 & -0.22 & 0.36 & 0.53 & 0.15 & -0.07 & & & & & & & & & \\
\hline 12. Posttest Positive Affect & 0.12 & 0.12 & 0.03 & 0.21 & 0.07 & -0.17 & -0.10 & -0.13 & -0.10 & 0.77 & -0.06 & & & & & & & & \\
\hline 13. Posttest Negative Affect & 0.10 & -0.07 & 0.35 & 0.02 & 0.06 & -0.23 & 0.36 & 0.53 & 0.17 & -0.08 & 0.84 & -0.08 & & & & & & & \\
\hline 14. Daily Diary Positive Affect & 0.08 & 0.16 & -0.02 & 0.17 & 0.04 & -0.07 & -0.24 & -0.27 & -0.12 & 0.63 & -0.20 & 0.71 & -0.19 & & & & & & \\
\hline 15. Daily Diary Negative Affect & 0.11 & -0.03 & 0.25 & -0.01 & 0.10 & -0.26 & 0.37 & 0.51 & 0.17 & -0.11 & 0.70 & -0.11 & 0.72 & -0.27 & & & & & \\
\hline 16. Daily Diary Risk Perceptions & 0.01 & -0.01 & 0.12 & -0.02 & 0.09 & -0.15 & 0.67 & 0.45 & 0.17 & -0.05 & 0.35 & -0.08 & 0.34 & -0.19 & 0.43 & & & & \\
\hline 17. Daily Diary Perceived Worry & 0.13 & -0.05 & 0.20 & -0.05 & 0.16 & -0.14 & 0.63 & 0.78 & 0.38 & -0.14 & 0.52 & -0.13 & 0.52 & -0.28 & 0.57 & 0.63 & & & \\
\hline 18. Daily Diary Health Behaviors & 0.22 & 0.16 & 0.20 & 0.15 & 0.22 & -0.20 & 0.21 & 0.35 & 0.21 & 0.13 & 0.32 & 0.15 & 0.34 & 0.13 & 0.33 & 0.12 & 0.35 & & \\
\hline 19. Age & -0.01 & -0.10 & -0.07 & -0.15 & -0.05 & 0.28 & -0.04 & -0.05 & 0.17 & -0.03 & -0.09 & -0.06 & -0.06 & -0.04 & -0.08 & -0.10 & -0.06 & -0.15 & \\
\hline Mean & $16.67 \%$ & 3.39 & 4.59 & 4.08 & 3.41 & 9.78 & 2.71 & 2.57 & 3.57 & 3.32 & 3.08 & 3.07 & 2.89 & 2.22 & 1.92 & 5.57 & 5.36 & 6.90 & 46.90 \\
\hline SD & $8.68 \%$ & 0.81 & 2.52 & 1.04 & 0.66 & 2.85 & 0.89 & 0.88 & 0.58 & 1.30 & 1.51 & 1.37 & 1.59 & 0.81 & 0.90 & 2.21 & 1.73 & 2.11 & 17.34 \\
\hline Reliability & 0.89 & 0.79 & 0.92 & 0.97 & - & 0.7 & 0.88 & 0.92 & 0.87 & 0.76 & 0.86 & 0.8 & 0.89 & $\begin{array}{r}\mathrm{RR}_{\mathrm{KF}} \\
=.99 ; \\
\mathrm{RC} \\
=76\end{array}$ & $\begin{array}{r}\mathrm{RR}_{\mathrm{KF}} \\
=.99 ; \\
\mathrm{RC} \\
=58\end{array}$ & $\begin{array}{r}\mathrm{RR}_{\mathrm{KF}} \\
=.99 ; \\
\quad R C \\
=70\end{array}$ & $\begin{array}{r}\mathrm{RR}_{\mathrm{KF}} \\
=.99 ; \\
\quad R C \\
=71\end{array}$ & $\begin{array}{r}\mathrm{RR}_{\mathrm{KF}} \\
=.97 ; \\
\quad R C \\
=38\end{array}$ & - \\
\hline $\mathrm{N}$ & 1297 & 1272 & 1297 & 1296 & 1280 & 1297 & 1086 & 1274 & 1283 & 1295 & 1296 & 1290 & 1290 & 627 & 627 & 585 & 627 & 627 & 1297 \\
\hline
\end{tabular}

Note: All reliability measures are alphas except for the daily diary measures. Between-person reliability is denoted as $R_{k f}$; estimating measurement precision regarding systematic between-person differences across days); within-person reliability is denoted as $R_{c}$; estimating measurement precision regarding systematic change of persons from day to day (Cranford et al., 2006). Bolded values are significant at $p<.05$; italicized values are marginally significant at $p<.1$. 


\section{Baseline Knowledge of COVID-19 and Emotion}

Knowledge of COVID-19. After answering the baseline health decision-making problem, participants read a brief paragraph about COVID-19, which included the entirety of information participants received about COVID-19: Many questions in this survey will be about the novel coronavirus, COVID-19. Coronavirus disease 2019 (COVID-19) is a respiratory illness that can spread from person-to-person. The virus that causes COVID-19 is a novel coronavirus that was first identified during an investigation into an outbreak in Wuhan, China. The first case of COVID19 in the United States was reported on January 21, 2020. After participants read this paragraph, they were asked, Overall, how would you rate your level of knowledge about COVID-19 (for example, what it is, how it is transmitted, how to protect yourself, etc.)? Their answers ranged from $1=$ "No knowledge at all" to $4=$ "A lot of knowledge." Participants could also choose "Do not know."

Negative and Positive Affect. Participants rated their current affective experience for five specific positively valenced (relief, amusement, affection, happiness, and interest) and six negatively valenced (disgust, sadness, fear, guilt, distress, and anger) emotion words on a likert scale $(1=$ "None" to 7 = "Strong;" Coifman et al., 2016). We created separate aggregate scores to index negative and positive emotions.

\section{Baseline Math Tasks}

The order of math attitudes and math anxiety measures was randomized. These measures were presented before the math skills measures because in past research (Sidney et al., 2019) participants reported more negative attitudes if they completed these math tasks before rating their attitudes. The order of the math skills measures was randomized for all participants. Unrelated to the current study's hypotheses, we also collected data on several math measures to ensure that 
random assignment to condition was successful (i.e., fraction equivalence [Fitzsimmons et al., in press], subjective numeracy [Fagerlin et al., 2007], and objective numeracy [Cokely et al., 2012]). Math Anxiety. Participants rated their overall math anxiety (Ashcraft, 2002) and math anxiety about specific types of numbers--whole numbers, fractions, percentages and whole number frequencies--for five items on a scale ranging from $1=$ "Not anxious" to $10=$ "Very anxious." We calculated an average math anxiety score across items.

Math Attitudes Questionnaire. Participants answered 20 questions (Sidney et al., 2019) pertaining to their attitudes about math in general as well as their specific attitudes about whole numbers, fractions, and percentages. This math attitudes questionnaire involves subscales for perceived ability, preferences, frequency of use, and importance. We calculated an average math attitude score across items.

Math Skills. Math skills were measured with number line estimation tasks for fractions, whole number frequencies, and percentages. In three blocks separated by type of number, participants made estimates for one fraction at a time (0-5 range; Siegler et al., 2011), one whole number frequency at a time ( 0 out of 100 to 100 out of 100 range), or one percentage at a time $(0 \%$ to $5 \%$ range). Participants completed 9 or 10 trials in each block. Participants' performance on each trial was measured as percent absolute error (Siegler \& Booth, 2004): PAE = ((|estimate true value $\mid) /$ numerical range) $* 100$. PAE was averaged across all trials with higher scores indicating greater error of estimation, or worse performance.

\section{Educational Intervention vs. Business-as-Usual Control}

Participants were randomly assigned to one of two experimental conditions: the educational intervention to combat whole number bias or the business-as-usual control condition. 
Educational Intervention Condition. Participants in the intervention condition were instructed to complete a diagram-based preparatory activity (Schwartz et al., 2011; Sidney \& Thompson, 2019) to visually illustrate that some numeric comparisons require taking both numerators and denominators into account by calculating a ratio. This preparatory activity, in a more familiar, concrete context (e.g., two orchards with differing rates of rotting apple trees; see Appendix E), was designed to facilitate drawing analogies to the COVID-19 context. Then, participants saw the number of deaths (numerator) and total \# infected (denominator) for both the flu and COVID-19 in a 2x2 contingency table (see Table 3 and Appendix E). Participants were instructed how to calculate and compare the COVID-19 vs. flu fatality rates via worked example, demonstrating each step in turn (McGinn et al., 2015), and were shown a horizontal bar graph comparing the fatality rates (Hamdan \& Gunderson, 2017; Sidney et al., 2019), thus leveraging empirical findings from cognitive science to help adults avoid WNB errors.

Business-as-Usual Control Condition. Control participants saw the same $2 \times 2$ contingency table as the educational intervention group. See Table 3 for the exact values shown. However, the control participants were not told which numbers to attend to in the contingency table, nor did they receive an analogy, a worked example to help them calculate the fatality rate, or a linear comparison of the fatality rates on a horizontal bar graph.

\section{Health Decision-Making}

Immediately after the intervention, participants completed three health decision-making problems (see Table 3). The first problem assessed whether participants considered the flu or COVID-19 to be more fatal based on the numbers presented in the problem. If they selected flu, that would be consistent with WNB. The second and third problems required transferring knowledge learned during the intervention about calculating rate (for those in the experimental 
condition) to novel contexts. In the first near transfer problem, participants were asked to think about the dynamic nature of the fatality rate. The fatality rate for COVID-19 decreased between January 30th and February 6th (based on statistics from the WHO Situation Reports). Thus, if participants simply guessed that fatality rates increased over time, they would get this problem wrong, and their response would be consistent with WNB. In the second far transfer problem, which was presented as a story problem, participants considered rates of infection across Italy and China $^{3}$. This problem tested whether participants were able to apply their understanding of fatality rates to infection rates. If participants selected that China has a higher infection rate, this response would be consistent with WNB. Decision accuracy was assessed for each problem with a forced choice question (e.g., Which disease is more fatal?). Health decision-making accuracy was scored as correct or incorrect, separately for each decision-making question.

\section{Strategy Reports and Coding}

In addition to response choice, we collected strategy reports that would indicate WNB errors. Participants provided immediate retrospective strategy reports for each of the four decisionmaking problems (one at baseline, three post-intervention) by explaining their responses in a text box in response to the prompt, Please describe in as much detail as possible how you made your decision about... (Fazio et al., 2017; Fitzsimmons et al., in press; Sidney, Thalluri, et al., 2019; Siegler et al., 2011; Siegler \& Thompson, 2014; Thompson et al., invited revision). Strategy reports can reflect the impact of experimental condition on health decision-making accuracy by allowing insight into the specific correct or incorrect methods individuals use to solve math problems (e.g., Siegler \& Thompson, 2014).

\footnotetext{
${ }^{3}$ We chose these two countries because they had large fatality counts at the time of the study, and it was only later that it was indicated that China may have held back on some numbers of infected/deaths (Bloomberg, 2020).
} 
The coding scheme included three codes to assess instances of WNB error: numerator, denominator, and larger numbers (see Appendix F for the full list of codes and descriptions). These codes reflected mentioning either the numerator or the denominator in isolation when making decisions (e.g., Look at the biggest number; How many died from it; Disease B has more people infected). For analyses, we collapsed across these three whole number bias codes. Participants who received one of the three WNB error codes but also reported a more mathematically-sophisticated strategy (i.e., indicated calculating a rate, including transformations to easier to handle numbers, such as decimals or percentages) were not included as having made WNB errors in the analyses reported below. Very few participants reported both rate and WNB strategies across the four health decision-making problems: baseline: $n=14(1 \%)$, post-intervention: $n=9(1 \%)$, near transfer: $n=5$ $(0 \%)$, far transfer: $n=12(1 \%)$.

Two coders (MM and ES) independently coded responses from 30 participants (for a total of 120 responses); interrater reliability was high (97\% interrater agreement across all codes and responses). The two raters resolved their disagreements through a conversation. MM then coded $13.3 \%$ and EA coded $87.7 \%$ of the remaining strategy reports.

Participants also rated their confidence after each health decision-making problem. Confidence judgments were not central to the current hypotheses and will not be discussed further.

\section{Post intervention Affect and Health Cognitions}

Negative and positive affect. This was the same measure administered at baseline.

Risk Perceptions. Risk perceptions (adapted from Klein \& Ferrer, 2018) were assessed as the perceived likelihood that oneself and close others would be infected with COVID-19 in the next year. Items assessing risk perceptions for oneself assessed absolute cognitive (“Overall, how likely is it that you will be infected with COVID-19 in the next year?"; 1 = "not at all likely" to 5 
$=$ "extremely likely;" 6 = "do not know"), comparative ("Overall, how do you think your chance of being infected with COVID-19 in the next year compares to other women or men of your age in the United States?"; 1 = "much less likely" to 5 = "much more likely;" 6 = "do not know"), and experiential risk ("I feel very vulnerable to being infected with COVID-19 in the next year"; $1=$ "strongly disagree" to 5 = "strongly agree;" 6 = "do not know"). Risk perceptions for others were assessed with the same three items and instead referenced "family members or friends." "Do not know" responses were coded as missing data. Risk perceptions for oneself and others were correlated $(r=0.69, p<.0001)$; thus, all six items were averaged to form one scale.

COVID-19 Worry. Worry (adapted from Taber et al., 2019 and Weinstein et al., 2007) was assessed as the extent of worry that oneself and close others would be infected with COVID19. Worry for oneself was assessed with two items: "How much do you worry about being infected with COVID-19?," and "How anxious are you about being infected with COVID-19?" (1 = "not at all" to $4=$ "a lot;"). Worry for others was assessed with the same two items but referenced "family members or friends." Worry for oneself and for others were correlated $(r=.76, p<.0001)$, thus all four items were averaged to form one scale.

\section{Post-Intervention Individual Differences Assessment}

These individual differences measures were administered in the same order for all participants at the end of the study. We did not expect responses to be influenced by exposure to the intervention condition. These measures were included as covariates in a subset of analyses.

Need for Cognition. This scale consists of the average of six items assessing the extent to which people enjoy engaging in the process of thinking (Cacioppo \& Petty, 1982; Coelho et al., 2018), given that computing and comparing ratios is cognitively demanding. A sample item includes: I would rather do something that requires little thought than something that is sure to 
challenge my thinking abilities. Participants rated themselves on a scale from $1=$ "Extremely Uncharacteristic" to $5=$ "Extremely Characteristic."

Health Literacy. The health literacy measure (Chew et al., 2008) included three items (i.e., confidence in filling out medical forms on own, have someone help read health materials, or have problems learning about a medical condition because of a difficulty understanding written materials). Participants rated themselves on a scale of $1=$ "None of the time/Not at all" to $5=$ "All of the time/Extremely." A health literacy score was computed as the sum of responses.

We also included a trait anxiety measure that was not central to the current hypotheses and thus is not discussed further.

\section{Daily Diaries (Days 2 through 11)}

For the ten days following the baseline assessment and intervention, participants were prompted via email each evening to answer questions about their emotional experiences, behaviors enacted, and perceptions of risk and worry related to COVID-19. Each of the indices demonstrated excellent measurement sensitivity both within $\left(\mathrm{R}_{\mathrm{C}}\right)$ and between $\left(\mathrm{R}_{\mathrm{KF}}\right)$ persons over the 10-day assessment period (Cranford et al., 2006). See Table 4.

Negative and Positive Affect. This was the same measure administered at baseline and post-intervention.

Preventive Health Behaviors. Participants reported the frequency of 13 behaviors (e.g., social distancing, hand washing, wearing masks, avoiding group activities; Appendix G) recommended broadly by public health experts and agencies (e.g., CDC). We summed the number of recommended behaviors participants reported engaging in at each diary signal so that each participant had a daily score of behaviors, 0-13. 
Risk Perceptions. Risk perceptions (adapted from Klein and Ferrer, 2018) were assessed with the two absolute cognitive risk items (i.e., risk for oneself and others) included at baseline (comparative and experiential risk items were not included due to the need for abbreviated measures in daily diaries). These two items were highly correlated $(r=0.83, p<.0001)$ and were averaged.

COVID-19 Worry. Worry (adapted from Weinstein et al., 2007) was assessed with the items from baseline concerning how much individuals worry about themselves and their family members and friends being infected with COVID-19. These two items were highly correlated $(r=$ $0.80, p<.0001)$ and were averaged.

\section{Overview of Analyses}

The data analysis plan was pre-registered on OSF before data collection began. Analyses concerning variables assessed in the baseline session were conducted in $R$ version 3.6.0 (R Core Team, 2019). First, we tested whether random assignment of participants to condition was successful in yielding equivalent groups at baseline for key variables. Analyses indicated that only gender was not equally distributed across conditions; thus, we controlled for gender in all subsequent analyses. Second, we conducted a series of logistic regressions testing the effects of condition (i.e., educational intervention vs. business-as-usual control) on each of the three postintervention health decision-making problems both in (1) simplified models controlling for gender alone, and in (2) "full" models. The full models controlled for gender, additional sociodemographic factors of age, race, educational attainment, expected predictors of rational number decision-making accuracy (i.e., magnitude knowledge [a composite score for PAE across three number line estimation scales], baseline health decision-making accuracy, math anxiety, math attitudes, health literacy, and need for cognition), and perceived COVID-19 knowledge. The 
majority of these covariates were specified in the pre-registration and were included to improve power by explaining greater variance in decision-making accuracy. We also covaried age and race because both factors have been associated with perceived disease risk (e.g., Taber et al., 2017). Third, we conducted three logistic regressions testing the effects of condition on WNB strategy reports for the three health decision-making problems assessed post-intervention, controlling for gender. Fourth, we conducted a series of linear regressions testing the effects of condition on COVID-19 risk perceptions, worry, and positive and negative affect immediately following the intervention while controlling for gender. We report the final fixed effects, including 95\% CIs, for our results below.

Finally, we examined the effect of condition on daily risk perceptions, worry, affect, and health behaviors reported during the 10 days of daily diaries by applying multilevel modeling (via SAS 9.4 Proc Mixed). For analyses examining daily risk perceptions, worry, and affect, the Level 1 predictor was day (diary order), and Level 2 predictors were experimental condition and gender. For the analysis examining health behaviors, we included affect in the model at both the state (Level 1) and trait (Level 2) level per current recommendations (Bolger \& Laurenceau, 2013) and because affect can be a motivating factor in behavior (Carver \& Scheier, 1998; Ekman, 1992). Hence, the models relating to affect had at Level 1: day, and person-centered deviations for negative and positive affect, and at Level 2: condition, gender, and person-mean levels of negative and positive affect across the diary. We used an autoregressive error structure in each analysis, and degrees of freedom were restricted to the number of participants (Bolger \& Laurenceau, 2013).

Finally, for the immediate dependent variables of risk perceptions, worry, and affect, as well as the daily diary dependent variables of risk perceptions, worry, affect, and health behaviors, we also ran models that controlled for gender and additional sociodemographic factors (i.e., age, 
race, educational attainment) and variables identified as significant predictors of health decision making accuracy post-intervention (i.e., percent absolute error, math anxiety, and baseline health decision making accuracy). These analyses were conducted to determine whether any effects of condition held when controlling for multiple factors expected to also predict these outcomes. 


\section{References}

Alibali, M. W., \& Sidney, P. G. (2015). Variability in the natural number bias: Who, when, how, and why. Learning and Instruction, 37, 56-61.

Alonso-Diaz, S., Cantlon, J. F., \& Piantadosi, S. T. (2019, July). Intrinsic whole number bias in an indigenous population. Poster presented at the 41st Annual Conference of the Cognitive Science Society. Montreal, Quebec, Canada.

Ashcraft, M. H. (2002). Math anxiety: Personal, educational, and cognitive consequences. Current Directions in Psychological Science, 11, 181-185.

Ashcraft, M. H., \& Krause, J. A. (2007). Working memory, math performance, and math anxiety. Psychonomic Bulletin \& Review, 14, 243-248.

Aspinwall, L. G., Taber, J. M., Kohlmann, W., Leaf, S. L., \& Leachman, S. A. (2014). Perceived risk following melanoma genetic testing: a 2-year prospective study distinguishing subjective estimates from recall. Journal of Genetic Counseling, 23, 421-437.

Barnett, S. M., \& Ceci, S. J. (2002). When and where do we apply what we learn?: A taxonomy for far transfer. Psychological Bulletin, 128, 612-637.

Behrend, T. S., Sharek, D. J., Meade, A. W., \& Wiebe, E. N. (2011). The viability of crowdsourcing for survey research. Behavior Research Methods, 43, 800-813.

Beilock, S. L., Gunderson, E. A., Ramirez, G., \& Levine, S. C. (2010). Female teachers' math anxiety affects girls' math achievement. Proceedings of the National Academy of Sciences, 107, 1860-1863.

Bloomberg (2020, April 2). China hits back at report that it hid Coronavirus numbers. Time. https://time.com/5814313/china-denies-hiding-coronavirus/

Bolger, N., \& Laurenceau, J.-P. (2013). Intensive longitudinal methods: An introduction to diary and experience sampling research. Guilford Press.

Bonato, M., Fabbri, S., Umiltà, C., \& Zorzi, M. (2007). The mental representation of numerical fractions: Real or integer?. Journal of Experimental Psychology: Human Perception and Performance, 33, 1410-1419.

Booth, J. L., McGinn, K. M., Barbieri, C., Begolli, K. N., Chang, B., Miller-Cotto, D., Young, L. K., \& Davenport, J. L. (2017). Evidence for cognitive science principles that impact learning in mathematics. In D. C. Geary, D. B. Berch, R. Ochsendorf, and K. M. Koepke (Eds.) Acquisition of complex arithmetic skills and higher-order mathematics concepts (pp. 297-325). Academic Press.

Bostrom, A. (2008). Lead is like mercury: Risk comparisons, analogies and mental models. Journal of Risk Research, 11, 99-117.

Braithwaite, D., Emery, J., Walter, F., Prevost, A. T., \& Sutton, S. (2004). Psychological impact of genetic counseling for familial cancer: a systematic review and meta-analysis. Journal of the National Cancer Institute, 96, 122-133.

Braithwaite, D. W., \& Siegler, R. S. (2018). Developmental changes in the whole number bias. Developmental Science, 21, e12541.

Braithwaite, D. W., \& Siegler, R. S. (2020). Putting fractions together. Journal of Educational Psychology, http://dx.doi.org/10.1037/edu0000477.

Brewer, N. T., Chapman, G. B., Gibbons, F. X., Gerrard, M., McCaul, K. D., \& Weinstein, N. D. (2007). Meta-analysis of the relationship between risk perception and health behavior: the example of vaccination. Health Psychology, 26(2), 136. 
Cacioppo, J. T., \& Petty, R. E. (1982). The need for cognition. Journal of Personality and Social Psychology, 42, 116-131.

Carver, C. S., \& Scheier, M. F. (1998). On the self-regulation of behavior. New York, NY, US: Cambridge University Press.

Centers for Disease Control and Prevention. (2020, April 17). 2019-2020 U.S. Flu season: Preliminary burden estimates. https://www.cdc.gov/flu/about/burden/preliminary-inseason-estimates.htm

Chapman, G. B., \& Coups, E. J. (2006). Emotions and preventive health behavior: worry, regret, and influenza vaccination. Health Psychology, 25, 82-90.

Chew, L. D., Griffin, J. M., Partin, M. R., Noorbaloochi, S., Grill, J. P., Snyder, A., ... \& VanRyn, M. (2008). Validation of screening questions for limited health literacy in a large VA outpatient population. Journal of General Internal Medicine, 23, 561-566.

Choi, S. S., Taber, J. M., Thompson, C. A., \& Sidney, P. G. (2020). Math anxiety, but not induced stress, is associated with objective numeracy. Journal of Experimental Psychology. Applied. Advance online publication. http://dx.doi.org/10.1037/xap0000268

Coelho, G.L.H., Hanel, P.H.P., \& Wolf, L.K. (2018). The very efficient assessment of need for cognition: Developing a six-item version. Assessment, 1, 1-16.

Coifman, K.G., Flynn, J.J. \& Pinto, L.A. (2016) When context matters: Negative emotions predict psychological health and adjustment. Motivation \& Emotion, 40, 602624.

Cokely, E. T., Galesic, M., Schulz, E., Ghazal, S., \& Garcia-Retamero, R. (2012). Measuring risk literacy: The Berlin numeracy test. Judgment and Decision Making, 7, 25-47.

Cranford, J. A., Shrout, P. E., Iida, M., Rafaeli, E., Yip, T., \& Bolger, N. (2006). A procedure for evaluating sensitivity to within-person change: Can mood measures in diary studies detect change reliably? Personality and Social Psychology Bulletin, 32, 917-929.

Cuite, C. L., Weinstein, N. D., Emmons, K., \& Colditz, G. (2008). A test of numeric formats for communicating risk probabilities. Medical Decision Making, 28, 377-384.

DeWolf, M., \& Vosniadou, S. (2015). The representation of fraction magnitudes and the whole number bias reconsidered. Learning and Instruction, 37, 39-49.

Dunlosky, J., Rawson, K. A., Marsh, E. J., Nathan, M. J., \& Willingham, D. T. (2013). Improving students' learning with effective learning techniques: Promising directions from cognitive and educational psychology. Psychological Science in the Public Interest, 14, 4-58.

Ekman, P. (1992). An argument for basic emotions. Cognition and Emotion, 6, 169-200.

Fagerlin, A., Zikmund-Fisher, B. J., Ubel, P. A., Jankovic, A., Derry, H. A., \& Smith, D. M. (2007). Measuring numeracy without a math test: Development of the Subjective Numeracy Scale (SNS). Medical Decision Making, 27,672-680.

Faust, J. M. (2020, April 28). Comparing COVID-19 deaths to Flu deaths is like comparing apples to oranges. Scientific American's Newsletters. https://blogs. scientificamerican. com/observations/comparing-covid-19-deaths-to-flu-deaths-islikecomparing-apples-to-oranges.

Faust, J. S., \& del Rio, C. (2020a). Assessment of deaths from COVID-19 and from seasonal influenza. JAMA Internal Medicine. https://doi.org/10.1001/jamainternmed.2020.2306

Faust, J., \& del Rio, C. (2020b). Relative disease burdens of COVID-19 and seasonal influenza in New York City, February 1-April 18, 2020. medRxiv. https://doi.org/10.1101/2020.04.22.20073551 
Fazio, L. K., DeWolf, M., \& Siegler, R. S. (2017). Strategy use and strategy choice in fraction magnitude comparison. Journal of Experimental Psychology: Learning, Memory and Cognition, 42, 1-16.

Fazio, L. K., Bailey, D. H., Thompson, C. A., \& Siegler, R. S. (2014). Relations of different types of numerical magnitude representations to each other and to mathematics achievement. Journal of Experimental Child Psychology, 123, 53-72.

Ferrer, R. A., \& Klein, W. M. (2015). Risk perceptions and health behavior. Current Opinion in Psychology, 5, 85-89.

Ferrer, R. A., Klein, W. M., Persoskie, A., Avishai-Yitshak, A., \& Sheeran, P. (2016). The tripartite model of risk perception (TRIRISK): distinguishing deliberative, affective, and experiential components of perceived risk. Annals of Behavioral Medicine, 50, 653-663.

Fitzsimmons, C., Thompson, C. A., \& Sidney, P. (in press). Do adults treat equivalent fractions equally? Adults' strategies and errors during fraction reasoning. Journal of Experimental Psychology: Learning, Memory, and Cognition.

Fitzsimmons, C., Thompson, C. A., Taber, J., \& Sidney, P. (in preparation). Does selfexplaining worked examples improve 5 th and 6 th grader's ability to solve hypothetical health decision-making word problems?

Floyd, D. L., Prentice-Dunn, S., \& Rogers, R. W. (2000). A meta-analysis of research on protection motivation theory. Journal of Applied Social Psychology, 30, 407-429.

Fuchs, L. S., Sterba, S. K., Fuchs, D., \& Malone, A. S. (2016). Does evidence-based fractions intervention address the needs of very low-performing students?. Journal of Research on Educational Effectiveness, 9, 662-677.

Furlong, E. E., \& Opfer, J. E. (2009). Cognitive constraints on how economic rewards affect cooperation. Psychological Science, 20, 11-16.

Galesic, M., \& Garcia-Retamero, R. (2013). Using analogies to communicate information about health risks. Applied Cognitive Psychology, 27, 33-42.

Gentner, D. (1983). Structure-mapping: A theoretical framework for analogy. Cognitive Science, 7, 155-170.

Gentner, D. (2003). Why we're so smart. In D. Gentner \& S. Goldin-Meadow (Eds.), Language in mind: Advances in the study of language and cognition (pp. 195-235). MIT Press.

Ghassemi, M., Bernecker, K., \& Brandstätter, V. (2020). “Take care, honey!”: People are more anxious about their significant others' risk behavior than about their own. Journal of Experimental Social Psychology, 86. https://doi.org/10.1016/j.jesp.2019.103879

Glanz, K., \& Bishop, D. B. (2010). The role of behavioral science theory in development and implementation of public health interventions. Annual Review of Public Health, 31, 399418. https://doi.org/10.1146/annurev.publhealth.012809.103604

Gómez, D. M., Jiménez, A., Bobadilla, R., Reyes, C., \& Dartnell, P. (2015). The effect of inhibitory control on general mathematics achievement and fraction comparison in middle school children. ZDM, 47, 801-811.

Halpern, D. F., Benbow, C. P., Geary, D. C., Gur, R. C., Hyde, J. S., \& Gernsbacher, M. A. (2007). The science of sex differences in science and mathematics. Psychological Science in the Public Interest, 8, 1-51.

Hamdan, N., \& Gunderson, E. A. (2017). The number line is a critical spatial-numerical representation: Evidence from a fraction intervention. Developmental Psychology, 53, 587-596. 
Hauser, D. J., \& Schwarz, N. (2016). Attentive Turkers: MTurk participants perform better on online attention checks than do subject pool participants. Behavior Research Methods, 48, 400-407.

Hay, J. L., McCaul K. D. , \& Magnan R. E. (2006). Does worry about breast cancer predict screening behaviors?. A meta-analysis of the prospective evidence. Preventative Medicine, 42, 401-408.

Heshka, J. T., Palleschi, C., Howley, H., Wilson, B., \& Wells, P. S. (2008). A systematic review of perceived risks, psychological and behavioral impacts of genetic testing. Genetics in Medicine, 10, 19-32.

Hutchison, J. E., Lyons, I. M., \& Ansari, D. (2019). More similar than different: Gender differences in children's basic numerical skills are the exception not the rule. Child Development, 90, e66-e79.

Johns Hopkins University and Medicine (2020, May 27). COVID-19 United States cases by county. https://coronavirus.jhu.edu/us-map

Kaminski, J. A., Sloutsky, V. M., Heckler, A. F. (2008). The advantage of abstract examples in learning math. Science, 320, 454-455.

Klahr, D., Chen, Z. (2011). Finding one's place in transfer space. Child Development Perspectives, 5, 196-204.

Klein, W. M., \& Ferrer, R. A. (2018). On being more amenable to threatening risk messages concerning close others (vis-a-vis the self). Personality and Social Psychology Bulletin, 44, 1411-1423.

Levine, S. C., Suriyakham, L. W., Rowe, M. L., Huttenlocher, J., \& Gunderson, E. A. (2010). What counts in the development of young children's number knowledge?. Developmental Psychology, 46, 1309-1319.

Lipkus, I. M., \& Peters, E. (2009). Understanding the role of numeracy in health: proposed theoretical framework and practical insights. Health Education \& Behavior, 36, 10651081.

McGinn, K. M., Lange, K. E., \& Booth, J. L. (2015). A worked example for creating worked examples. Mathematics Teaching in the Middle School, 21, 26-33.

Meyerson, P., \& Tryon, W. W. (2003). Validating Internet research: A test of the psychometric equivalence of Internet and in-person samples. Behavior Research Methods, Instruments, \& Computers, 35, 614-620.

Michie, S., Van Stralen, M. M., \& West, R. (2011). The Behaviour Change Wheel: A new method for characterising and designing behaviour change interventions. Implementation Science, 6(1), 42. https://doi.org/10.1186/1748-5908-6-42

Nelson, W., Reyna, V. F., Fagerlin, A., Lipkus, I., \& Peters, E. (2008). Clinical implications of numeracy: theory and practice. Annals of Behavioral Medicine, 35, 261-274.

Netburn, D. (2020, March 5). The flu has killed far more people than coronavirus. So why all the frenzy about COVID-19?. Los Angeles Times. https://www.latimes.com/science/story/2020-03-05/flu-killed-more-people-coronaviruscovid-19

Newcombe, N. S., Booth, J. L., \& Gunderson, E. A. (2019) Spatial skills, reasoning, and mathematics. In J. Dunlosky and K. A. Rawson (Eds.) Cambridge handbook of cognition and education (pp. 100-123). Cambridge University Press.

Ni, Y., \& Zhou, Y. D. (2005). Teaching and learning fraction and rational numbers: The origins and implications of whole number bias. Educational Psychologist, 40, 27-52. 
NMAP (2008). Foundations for success: Report of the National Mathematics Advisory Board Panel: U.S. Government Printing Office.

Obersteiner, A., Van Dooren, W., Van Hoof, J., \& Verschaffel, L. (2013). The natural number bias and magnitude representation in fraction comparison by expert mathematicians. Learning and Instruction, 28, 64-72.

Opfer, J. E., \& DeVries, J. M. (2008). Representational change and magnitude estimation: Why young children can make more accurate salary comparisons than adults. Cognition, 108, 843-849.

Peters, E. (2012). Beyond comprehension: The role of numeracy in judgments and decisions. Current Directions in Psychological Science, 21, 31-35.

Peters, E., \& Bjalkebring, P. (2015). Multiple numeric competencies: When a number is not just a number. Journal of Personality and Social Psychology, 108, 802-822.

Portnoy, D. B., Kaufman, A. R., Klein, W. M., Doyle, T. A., \& de Groot, M. (2014). Cognitive and affective perceptions of vulnerability as predictors of exercise intentions among people with type 2 diabetes. Journal of Risk Research, 17, 177-193.

Pruden, S. M., Levine, S. C., \& Huttenlocher, J. (2011). Children's spatial thinking: Does talk about the spatial world matter?. Developmental Science, 14, 1417-1430.

R Core Team (2019). R: A language and environment for statistical computing. R

Foundation for Statistical Computing, Vienna, Austria. URL

https://www.R-project.org/.

Renkl, A. (2014). Toward an instructionally oriented theory of example-based learning. Cognitive Science, 38, 1-37.

Rettner, R. (2020, May 14). How does the new coronavirus compare with the flu? Live Science. https:/www.livescience.com/new-coronavirus-compare-with-flu.html

Reyna, V. F., \& Brainerd, C. J. (2008). Numeracy, ratio bias, and denominator neglect in judgments of risk and probability. Learning and Individual Differences, 18, 89-107.

Reyna, V. F., Nelson, W. L., Han, P. K., \& Dieckmann, N. F. (2009). How numeracy influences risk comprehension and medical decision making. Psychological Bulletin, 135, 943-973.

Rittle-Johnson, B., Siegler, R. S., \& Alibali, M. W. (2001). Developing conceptual understanding and procedural skill in mathematics: An iterative process. Journal of Educational Psychology, 93, 346-362.

Rivers, M., Fitzsimmons, C., Fisk, S., Dunlosky, J., \& Thompson, C. A. (under review). Metaanalytic review of gender differences in performance and confidence in number line estimation.

Roberts, D. C. (2020, May 22). Putting the risk of Covid-19 in perspective. The New York Times. https://www.nytimes.com/2020/05/22/well/live/putting-the-risk-of-covid-19-inperspective.html

Rosenstock, I.M. (1990). The health belief model: Explaining health behavior through expectancies. In K. Glanz, F. M. Lewis \& B. K. Rimer (Eds.), Health behavior and health education: Theory, research, and practice. (pp. 39-62). Jossey-Bass.

Rothman, A. J., Simpson, J. A., Huelsnitz, C. O., Jones, R. E., \& Scholz, U. (2020). Integrating intrapersonal and interpersonal processes: a key step in advancing the science of behavior change. Health Psychology Review, 14, 182-187.

Schneider, M., \& Siegler, R. S. (2010). Representations of the magnitudes of fractions. Journal of Experimental Psychology: Human Perception and Performance, 36, 1227-1238. 
Schwartz, D. L., Chase, C. C., Oppezzo, M. A., \& Chin, D. B. (2011). Practicing versus inventing with contrasting cases: The effects of telling first on learning and transfer. Journal of Educational Psychology, 103, 759-775.

Shabad, A. (2020, May 28). CDC estimates COVID 19 mortality rate is $0.4 \%$, significantly lower than previously reported. https:/www.wcnc.com/article/news/health/coronavirus/datacdc-estimates-covid-19-mortality-rate/275-fc43f37f-6764-45e3-b615-123459f0082b

Sheeran, P., Harris, P. R., \& Epton, T. (2014). Does heightening risk appraisals change people's intentions and behavior? A meta-analysis of experimental studies. Psychological Bulletin, $140(2), 511$.

Sidney, P., \& Thompson, C.A. (2019). Supporting children's analogical learning by "warming up" with relevant prior knowledge. Current Directions in Psychological Science, 28, 619625.

Sidney, P. G., Thalluri, R., Buerke, M. L., \& Thompson, C. A. (2019). Who uses more strategies? Linking mathematics anxiety to adults' strategy variability and performance on fraction magnitude tasks. Thinking \& Reasoning, 25, 94-131.

Sidney, P. G., Thompson, C. A., Fitzsimmons, C., \& Taber, J. M. (2019). Children's and Adults' Math Attitudes Are Differentiated by Number Type. The Journal of Experimental Education, 1-32.

Sidney, P., Thompson, C. A., \& Rivera, F. (2019). Number lines, but not area models, support children's accuracy and conceptual models of fraction division. Contemporary Educational Psychology, 58, 288-298.

Siegler, R. S., \& Booth, J. L. (2004). Development of numerical estimation in young children. Child Development, 75, 428-444.

Siegler, R. S., \& Thompson, C. A. (2014). Numerical landmarks are useful-except when they're not. Journal of Experimental Child Psychology, 120, 39-58.

Siegler, R. S., Thompson, C. A., \& Schneider, M. (2011). An integrated theory of whole number and fractions development. Cognitive Psychology, 62, 273-296.

Siegler, R. S. (2016). Magnitude knowledge: The common core of numerical development. Developmental Science, 19, 341-361.

Star, J. R., Rittle-Johnson, B., \& Durkin, K. (2016). Comparison and explanation of multiple strategies: One example of a small step forward for improving mathematics education. Policy Insights from the Behavioral and Brain Sciences, 3, 151-159.

Stokols, D. (1996). Translating social ecological theory into guidelines for community health promotion. American Journal of Health Promotion, 10, 282-298. https://doi.org/10.4278\%2F0890-1171-10.4.282

Taber, J. M., Aspinwall, L. G., Drummond, D. M., Stump, T. K., Kohlmann, W., Champine, M., ... \& Leachman, S. A. (2020). Priority of risk (but not perceived magnitude of risk) predicts improved sun-protection behavior following genetic counseling for familial melanoma. Annals of Behavioral Medicine. https://doi.org/10.1093/abm/kaaa028

Taber, J. M., Klein, W. M., Suls, J. M., \& Ferrer, R. A. (2017). Lay awareness of the relationship between age and cancer risk. Annals of Behavioral Medicine, 51, 214-225.

Taber, J. M., McQueen, A., Simonovic, N., \& Waters, E. A. (2019). Adapting a self-affirmation intervention for use in a mobile application for smokers. Journal of Behavioral Medicine, 42, 1050-1061.

The Lancet Infectious Diseases. (2020). COVID-19: Endgames [Editorial]. The Lancet, $20,511$. 
Thompson, C. A., \& Opfer, J. E. (2008). Costs and benefits of representational change: Effects of context on age and sex differences in magnitude estimation. Journal of Experimental Child Psychology, 101, 20-51.

Thompson, C. A., Taber, J. M., Coifman, K.G., \& Sidney, P. (2020, April 8) Math misconceptions may lead people to underestimate the true threat of COVID-19. The Conversation. https://theconversation.com/math-misconceptions-may-lead-people-tounderestimate-the-true-threat-of-covid-19-134520

Thompson, C. A., Taber, J. M., Fitzsimmons, C., \& Sidney, P. (invited revision). Strategy reports involving attention to math are associated with accurate responses on a numeric health decision-making problem.

Torbeyns, J., Schneider, M., Xin, Z. \& Siegler, R. S. (2015). Bridging the gap: Fraction understanding is central to mathematics achievement in students from three different continents. Learning and Instruction, 37, 5-13.

United States Census Bureau (2018). Quick facts. Retrieved from:

https://www.census.gov/quickfacts/fact/table/US/SBO030212

Vamvakoussi, X. (2015). The development of rational number knowledge: Old topic, new insights. Learning and Instruction, 37, 50-55.

Vamvakoussi, X., \& Vosniadou, S. (2010). How many decimals are there between two fractions? Aspects of secondary school students' understanding of rational numbers and their notation. Cognition and Instruction, 28, 181-209.

Van Hoof, J., Verschaffel, L., De Neys, W., \& Van Dooren, W. (2020). Intuitive errors in learners' fraction understanding: A dual-process perspective on the natural number bias. Memory \& Cognition. https://doi.org/10.3758/s13421-020-01045-1

Vosniadou, S. (2014). Examining cognitive development from a conceptual change point of view: The framework theory approach. European Journal of Developmental Psychology, 11, 645-661.

Walker, M. (2020, April 27) COVID-19 No Worse Than the Flu? Hardly: New York City data show dramatic imbalance. MedPage Today. https://www.medpagetoday.com/infectiousdisease/covid19/86176

Waters, E. A., Weinstein, N. D., Colditz, G. A., \& Emmons, K. M. (2007). Reducing aversion to side effects in preventive medical treatment decisions. Journal of Experimental Psychology: Applied, 13, 11-21.

Weinstein, N. D., \& Klein, W. M. (1995). Resistance of personal risk perceptions to debiasing interventions. Health Psychology, 14, 132-140.

Weinstein, N. D., Kwitel, A., McCaul, K. D., Magnan, R. E., Gerrard, M., \& Gibbons, F. X. (2007). Risk perceptions: Assessment and relationship to influenza vaccination. Health Psychology, 26, 146-151.

Witte, K. (1992). Putting the fear back into fear appeals: The extended parallel process model. Communication Monographs, 59, 329-349. doi: 10.1080/03637759209376276 World Health Organization (2020). Novel Coronavirus (2019-nCoV): Situation report 13. https:/www.who.int/docs/default-source/coronaviruse/situation-reports/20200202sitrep-13-ncov-v3.pdf?sfvrsn=195f4010_6

Yan, H. (2020, May 1). Critics said the flu kills more than coronavirus. Why that's not a fair comparison -- and now, it's not even true. CNN.

https://www.cnn.com/2020/05/01/health/flu-vs-coronavirus-deaths/index.html 
Yu, S., Kim, D., Mielicki, M. K., Fitzsimmons, C., Thompson, C. A., \& Opfer, J. E. (in press). From integers to fractions: Developing a coherent understanding of proportional magnitude. In S. Denison, M. Mack, Y. Xu, and B.C. Armstrong (Eds.) Proceedings of the 41st annual conference of the Cognitive Science Society. Cognitive Science Society. 


\section{Supplemental Materials}

Appendix A: Statistical models for health decision-making accuracy, WNB strategy reports, and baseline risk perceptions, worry, positive and negative affect

Appendix B: Statistical models for 10 days of daily diaries

Appendix C: Survey flow

Appendix D: Exclusion criteria

Appendix E: Information presented as part of the educational intervention and control condition Appendix F: Health decision-making strategy usage

Appendix G: Daily diary behaviors 


\section{Appendix A.}

Full models for logistic regressions on health decision-making accuracy.

Table A1. Logistic regression effects on health decision making accuracy for immediate posttest.

\begin{tabular}{llrrrr}
\hline & & $\boldsymbol{b}(\boldsymbol{S E})$ & $\mathbf{Z}$ & $\boldsymbol{p}$ & OR, [95\% CI of OR] \\
\hline \multirow{2}{*}{ Model 1 } & Intercept & $0.11(0.10)$ & 1.11 & .265 & $1.12,[0.92,1.37]$ \\
& Condition & $1.31(0.14)$ & 9.66 & $<.001$ & $3.71,[2.85,4.85]$ \\
& Male & $0.62(0.13)$ & 4.64 & $<.001$ & $1.85,[1.43,2.41]$
\end{tabular}

Model 1 vs. null model, $\chi^{2}(2)=117.08, p<.001$

\begin{tabular}{lrrrr} 
Intercept & $-0.57(0.69)$ & -0.84 & .403 & $0.56,[0.15,2.17]$ \\
Condition & $1.42(0.15)$ & 9.56 & $<.001$ & $4.14,[3.11,5.57]$ \\
Male & $0.31(0.16)$ & 1.96 & .049 & $1.37,[1.00,1.88]$ \\
Baseline Health Decision Making & $1.19(0.16)$ & 7.20 & $<.001$ & $3.27,[2.38,4.55]$ \\
Accuracy & $-4.40(0.97)$ & -4.54 & $<.001$ & $0.01,[<0.01,0.08]$ \\
Percent Absolute Error & $-0.03(0.03)$ & -0.87 & .384 & $0.97,[0.91,1.04]$ \\
Math Anxiety & $0.05(0.08)$ & 0.64 & .524 & $1.05,[0.90,1.24]$ \\
Math Attitudes & $<0.01(<0.01)$ & 0.14 & .889 & $1.00,[0.99,1.01]$ \\
Age & $0.32(0.17)$ & 1.94 & .052 & $1.38,[1.00,1.91]$ \\
White vs. non-white & $0.11(0.22)$ & 0.49 & .623 & $1.12,[0.72,1.74]$ \\
a'Education (Bachelors) & $<0.01(0.27)$ & $<0.01$ & .998 & $1.00,[0.59,1.72]$ \\
aEducation (Graduate Degree) & $-0.06(0.17)$ & -0.35 & .725 & $0.94,[0.67,1.32]$ \\
aEducation (Some College or & $0.16(0.11)$ & 1.45 & .147 & $1.17,[0.94,1.46]$ \\
Associates) & $0.01(0.03)$ & 0.23 & .820 & $1.01,[0.95,1.07]$ \\
Perceived COVID-19 Knowledge & $0.05(0.10)$ & 0.51 & .613 & $1.05,[0.86,1.28]$ \\
Health Literacy & & & & \\
\hline Need for Cognition & & & \\
\hline
\end{tabular}

Note: ${ }^{a}$ Each level of education is compared to participants who reported having a high school education or less. Condition was coded as $1=$ intervention and $0=$ control. 
Table A2. Logistic regression effects on health decision making accuracy for the near transfer problem.

\begin{tabular}{|c|c|c|c|c|c|}
\hline & & $b(S E)$ & $\mathbf{Z}$ & & OR $[95 \%$ CI of OR] \\
\hline \multirow{3}{*}{ Model 1} & Intercept & $-1.53(0.12)$ & -12.82 & $<.001$ & $0.22[0.17,0.27]$ \\
\hline & Condition & $0.35(0.13)$ & 2.69 & .007 & $1.41[1.10,1.82]$ \\
\hline & Male & $0.64(0.13)$ & 4.95 & $<.001$ & $1.89[1.47,2.43]$ \\
\hline \multicolumn{6}{|c|}{ Model 1 vs. null model, $\mathrm{X}^{2}(2)=30.49, p<.001$} \\
\hline & Intercept & $-2.20(0.74)$ & -2.98 & .003 & $0.11[0.03,0.47]$ \\
\hline & Condition & $0.40(0.14)$ & 2.73 & .006 & $1.48[1.12,1.98]$ \\
\hline & Male & $0.30(0.16)$ & 1.90 & .058 & $1.35[0.99,1.85]$ \\
\hline & Baseline Health Decision Making & $0.94(0.15)$ & 6.16 & $<.001$ & $2.56[1.90,3.46]$ \\
\hline & Percent absolute error (PAE) & $-7.10(1.11)$ & -6.41 & $<.001$ & $<0.01[<0.01,0.01]$ \\
\hline & Math Anxiety & $-0.08(0.03)$ & -2.37 & .018 & $0.92[0.86,0.99]$ \\
\hline & Math Attitudes & $0.11(0.10)$ & 1.17 & 242 & $1.12[0.93,1.36]$ \\
\hline \multirow[t]{8}{*}{ Model 2} & Age & $0.01(<0.01)$ & 1.24 & 215 & $1.01[1.00,1.02]$ \\
\hline & White vs. non-white & $0.05(0.18)$ & 0.25 & .801 & $1.05[0.74,1.49]$ \\
\hline & ${ }^{\mathrm{a} E d u c a t i o n}$ (Bachelors) & $0.11(0.22)$ & 0.49 & .624 & $1.11[0.73,1.70]$ \\
\hline & ${ }^{\mathrm{a} E}$ Education (Graduate Degree) & $-0.11(0.26)$ & -0.40 & 686 & $0.90[0.54,1.49]$ \\
\hline & $\begin{array}{l}\text { aEducation (Some College or } \\
\text { Associates) }\end{array}$ & $-0.11(0.20)$ & -0.55 & .584 & $0.90[0.61,1.32]$ \\
\hline & COVID Knowledge & $0.01(0.12)$ & 0.05 & 959 & $1.01[0.80,1.27]$ \\
\hline & Health Literacy & $0.05(0.03)$ & 1.55 & .122 & $1.06[0.99,1.13]$ \\
\hline & Need for Cognition & $0.12(0.10)$ & 1.13 & .259 & $1.12[0.92,1.37]$ \\
\hline \multicolumn{6}{|c|}{ Model 2 vs. null model, $\mathrm{X}^{2}(14)=255.79, p<.001$} \\
\hline
\end{tabular}

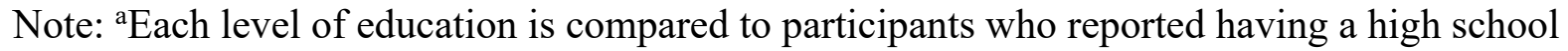
education or less. Condition was coded as $1=$ intervention and $0=$ control. 
Table A3. Logistic regression effects on health decision making accuracy for the far transfer problem.

\begin{tabular}{|c|c|c|c|c|c|}
\hline & & $b(S E)$ & $\mathbf{Z}$ & $p$ & OR $[95 \%$ CI of OR] \\
\hline \multirow{3}{*}{ Model 1} & Intercept & $0.27(0.10)$ & 2.78 & .005 & $1.31[1.08,1.59]$ \\
\hline & Condition & $-0.04(0.11)$ & -0.32 & .747 & $0.96[0.77,1.21]$ \\
\hline & Male & $0.33(0.11)$ & 2.90 & .004 & $1.39[1.11,1.74]$ \\
\hline \multicolumn{6}{|c|}{ Model 1 vs. null model, $\mathrm{X}^{2}(2)=8.71, p=.0129$} \\
\hline \multirow{15}{*}{ Model 2} & Intercept & $-0.69(0.62)$ & -1.11 & .266 & $0.50[0.15,1.70]$ \\
\hline & Condition & $-0.09(0.13)$ & -0.70 & .486 & $0.91[0.71,1.18]$ \\
\hline & Male & $0.21(0.14)$ & 1.47 & .140 & $1.24[0.93,1.64]$ \\
\hline & Baseline Health Decision Making & $1.21(0.14)$ & 8.55 & $<.001$ & $3.35[2.55,4.44]$ \\
\hline & Percent Absolute Error & $-5.64(0.89)$ & -6.36 & $<.001$ & $<0.01[<0.01,0.02]$ \\
\hline & Math Anxiety & $-0.03(0.03)$ & -1.01 & .311 & $0.97[0.92,1.03]$ \\
\hline & Math Attitudes & $0.09(0.08)$ & 1.15 & .252 & $1.09[0.94,1.27]$ \\
\hline & Age & $0.01(<0.01)$ & 1.94 & .052 & $1.01[1.00,1.02]$ \\
\hline & White vs. non-white & $-0.10(0.15)$ & -0.66 & .508 & $0.90[0.67,1.22]$ \\
\hline & ${ }^{\text {aEducation (Bachelors) }}$ & $-0.14(0.20)$ & -0.70 & .486 & $0.87[0.59,1.28]$ \\
\hline & ${ }^{\mathrm{a} E d u c a t i o n}$ (Graduate Degree) & $-0.13(0.24)$ & -0.56 & .577 & $0.87[0.55,1.40]$ \\
\hline & $\begin{array}{l}\text { aEducation (Some College or } \\
\text { Associates) }\end{array}$ & $0.16(0.16)$ & 1.03 & .301 & $1.18[0.86,1.61]$ \\
\hline & COVID Knowledge & $0.11(0.10)$ & 1.10 & .272 & $1.12[0.92,1.37]$ \\
\hline & Health Literacy & $0.08(0.03)$ & 2.91 & .004 & $1.09[1.03,1.15]$ \\
\hline & Need for Cognition & $-0.06(0.09)$ & -0.63 & .527 & $0.94[0.79,1.13]$ \\
\hline
\end{tabular}

Model 2 vs. null model, $\mathrm{X}^{2}(14)=249.59, p<.0001$

Note: ${ }^{\mathrm{E} E a c h}$ level of education is compared to participants who reported having a high school education or less. Condition was coded as $1=$ intervention and $0=$ control. 


\section{Whole number bias in strategy reports}

Table A4. Logistic regression effects on whole number bias errors reported in strategy reports for immediate posttest.

\begin{tabular}{|c|c|c|c|c|c|}
\hline & & $b(S E)$ & $\mathbf{Z}$ & $p$ & OR $[95 \% \mathrm{CI}]$ \\
\hline \multirow{3}{*}{ Model 1} & Intercept & $-1.32(0.12)$ & -10.63 & $<.001$ & $0.27[0.21,0.34]$ \\
\hline & Condition & $-0.74(0.17)$ & -4.48 & $<.001$ & $0.48[0.34,0.66]$ \\
\hline & Male & $-0.33(0.16)$ & -2.03 & .042 & $0.72[0.52,0.99]$ \\
\hline \multicolumn{6}{|c|}{ Model 1 vs. null model, $\mathrm{X}^{2}(2)=24.01, p<.001$} \\
\hline \multirow{15}{*}{ Model 2} & Intercept & $-1.19(0.83)$ & -1.44 & .151 & $0.30[0.06,1.53]$ \\
\hline & Condition & $-0.90(0.19)$ & -4.78 & $<.001$ & $0.41[0.28,0.59]$ \\
\hline & Male & $-0.04(0.20)$ & -0.18 & .859 & $0.96[0.65,1.43]$ \\
\hline & Baseline Whole Number Bias & $1.88(0.19)$ & 9.88 & $<.001$ & $6.53[4.52,9.53]$ \\
\hline & Percent Absolute Error & $2.93(1.18)$ & 2.47 & .013 & $18.64[1.83,189.91]$ \\
\hline & Math Anxiety & $0.10(0.04)$ & 2.38 & .018 & $1.10[1.02,1.19]$ \\
\hline & Math Attitudes & $-0.01(0.10)$ & -0.08 & .935 & $0.99[0.81,1.21]$ \\
\hline & Age & $-0.01(0.01)$ & -2.17 & .030 & $0.99[0.98,1.00]$ \\
\hline & White vs. non-white & $-0.17(0.21)$ & -0.82 & .414 & $0.84[0.57,1.27]$ \\
\hline & aEducation (Bachelors) & $-0.48(0.29)$ & -1.65 & .099 & $0.62[0.35,1.08]$ \\
\hline & ${ }^{\mathrm{a}}$ Education (Graduate Degree) & $-0.76(0.40)$ & -1.89 & .059 & $0.47[0.20,0.99]$ \\
\hline & $\begin{array}{l}\text { aEducation (Some College or } \\
\text { Associates) }\end{array}$ & $-0.19(0.21)$ & -0.89 & .372 & $0.83[0.55,1.25]$ \\
\hline & COVID Knowledge & $-0.16(0.14)$ & -1.11 & .269 & $0.86[0.65,1.13]$ \\
\hline & Health Literacy & $-0.02(0.04)$ & -0.53 & .599 & $0.98[0.91,1.05]$ \\
\hline & Need for Cognition & $-0.11(0.13)$ & -0.84 & .402 & $0.90[0.69,1.16]$ \\
\hline
\end{tabular}

Note: aEach level of education is compared to participants who reported having a high school education or less. Condition was coded as $1=$ intervention and $0=$ control. 
Table A5. Logistic regression effects on whole number bias errors reported in strategy reports on the near transfer problem.

\begin{tabular}{|c|c|c|c|c|c|}
\hline & & $b(S E)$ & $\mathbf{Z}$ & $p$ & OR $[95 \% \mathrm{CI}]$ \\
\hline \multirow{3}{*}{ Model 1} & Intercept & $-0.87(0.11)$ & -7.95 & $<.001$ & $0.42[0.34,0.52]$ \\
\hline & Condition & $-0.29(0.14)$ & -2.13 & .033 & $0.75[0.57,0.98]$ \\
\hline & Male & $-0.72(0.14)$ & -5.00 & $<.001$ & $0.49[0.37,0.65]$ \\
\hline
\end{tabular}

Model 1 vs. null model, $\mathrm{X}^{2}(2)=29.38, p<.001$

\begin{tabular}{|c|c|c|c|c|c|}
\hline & Intercept & $-1.29(0.73)$ & -1.79 & .074 & $0.27[0.07,1.13]$ \\
\hline & Condition & $-0.40(0.16)$ & -2.55 & .011 & $0.67[0.49,0.91]$ \\
\hline & Male & $-0.56(0.18)$ & -3.21 & .001 & $0.57[0.40,0.80]$ \\
\hline & Baseline Whole Number Bias & $1.51(0.16)$ & 9.50 & $<.001$ & $4.51[3.31,6.17]$ \\
\hline & Percent Absolute Error & $3.64(1.02)$ & 3.57 & $<.001$ & $38.20[5.17,284.19]$ \\
\hline & Math Anxiety & $0.06(0.03)$ & 1.75 & .081 & $1.06[0.99,1.14]$ \\
\hline & Math Attitudes & $-0.09(0.09)$ & -1.06 & .289 & $0.91[0.76,1.08]$ \\
\hline Model 2 & Age & $-0.01(<.01)$ & -2.23 & .026 & $0.99[0.98,1.00]$ \\
\hline & White vs. non-white & $-0.24(0.18)$ & -1.33 & .182 & $0.79[0.56,1.12]$ \\
\hline & ${ }^{\text {aEducation (Bachelors) }}$ & $-0.11(0.24)$ & -0.47 & .642 & $0.90[0.56,1.42]$ \\
\hline & ${ }^{\mathrm{a} E d u c a t i o n ~(G r a d u a t e ~ D e g r e e) ~}$ & $-0.53(0.33)$ & -1.61 & .108 & $0.59[0.30,1.10]$ \\
\hline & $\begin{array}{l}\text { "Education (Some College or } \\
\text { Associates) }\end{array}$ & $-0.25(0.18)$ & -1.36 & .175 & $0.78[0.55,1.1$ \\
\hline & COVID Knowledge & $0.03(0.12)$ & 0.26 & .797 & $1.03[0.81,1.31]$ \\
\hline & Health Literacy & $0.01(0.03)$ & 0.45 & .654 & $1.01[0.95,1.08]$ \\
\hline & Need for Cognition & $-0.05(0.11)$ & -0.44 & .659 & $0.95[0.77,1.18]$ \\
\hline
\end{tabular}

Note: ${ }^{a}$ Each level of education is compared to participants who reported having a high school education or less. Condition was coded as $1=$ intervention and $0=$ control. 
Table A6. Logistic regression effects on whole number bias errors reported in strategy reports on the far transfer problem.

\begin{tabular}{|c|c|c|c|c|c|}
\hline & & $b(S E)$ & $\mathbf{Z}$ & $p$ & OR, $[95 \% \mathrm{CI}]$ \\
\hline \multirow{3}{*}{ Model 1} & Intercept & $-1.20(0.12)$ & -10.38 & $<.001$ & $0.30,[0.24,0.38]$ \\
\hline & Condition & $-0.11(0.14)$ & -0.82 & .411 & $0.89,[0.68,1.17]$ \\
\hline & Male & $-0.21(0.14)$ & -1.50 & .135 & $0.81,[0.62,1.07]$ \\
\hline \multicolumn{6}{|c|}{ Model 1 vs. null model, $\mathrm{X}^{2}(2)=2.79, p=.248$} \\
\hline \multirow{15}{*}{ Model 2} & Intercept & $-1.96(0.71)$ & -2.76 & .006 & $0.14,[0.03,0.56]$ \\
\hline & Condition & $-0.13(0.15)$ & -0.88 & .380 & $0.88,[0.66,1.17]$ \\
\hline & Male & $0.05(0.17)$ & 0.28 & .776 & $1.05,[0.76,1.45]$ \\
\hline & Baseline Whole Number Bias & $0.96(0.16)$ & 6.11 & $<.001$ & $2.60,[1.92,3.54]$ \\
\hline & Percent Absolute Error & $2.17(0.99)$ & 2.20 & .028 & $8.74,[1.26,60.36]$ \\
\hline & Math Anxiety & $0.10(0.03)$ & 2.98 & .003 & $1.10,[1.03,1.18]$ \\
\hline & Math Attitudes & $-0.17(0.09)$ & -2.05 & .041 & $0.84,[0.71,0.99]$ \\
\hline & Age & $-0.02(<0.01)$ & -3.29 & .001 & $0.98,[0.97,0.99]$ \\
\hline & White vs. non-white & $0.26(0.18)$ & 1.43 & .152 & $1.29,[0.91,1.84]$ \\
\hline & a'Education (Bachelors) & $-0.43(0.23)$ & -1.90 & .057 & $0.65,[0.41,1.01]$ \\
\hline & ${ }^{\mathrm{a} E d u c a t i o n}$ (Graduate Degree) & $-0.44(0.29)$ & -1.55 & .121 & $0.64,[0.36,1.11]$ \\
\hline & $\begin{array}{l}{ }^{\mathrm{a} E d u c a t i o n} \text { (Some College or } \\
\text { Associates) }\end{array}$ & $-0.43(0.18)$ & -2.43 & .015 & $0.65,[0.46,0.92]$ \\
\hline & COVID Knowledge & $0.05(0.12)$ & 0.43 & .668 & $1.05,[0.84,1.33]$ \\
\hline & Health Literacy & $0.05(0.03)$ & 1.68 & .094 & $1.06,[0.99,1.12]$ \\
\hline & Need for Cognition & $0.09(0.11)$ & 0.81 & .419 & $1.09,[0.89,1.34]$ \\
\hline
\end{tabular}

Note: ${ }^{a}$ Each level of education is compared to participants who reported having a high school education or less. Condition was coded as $1=$ intervention and $0=$ control. 
Table A7. Linear regression effects on baseline risk perceptions.

\begin{tabular}{|c|c|c|c|c|c|}
\hline & & $b(S E)$ & $t$ & $p$ & $95 \% \mathrm{CI}$ \\
\hline \multirow{3}{*}{ Model 1} & Intercept & $2.73(0.05)$ & 58.00 & $<.001$ & {$[2.64,2.82]$} \\
\hline & Condition & $-0.02(0.05)$ & -0.31 & .759 & {$[-0.12,0.09]$} \\
\hline & Male & $-0.02(0.05)$ & -0.33 & .741 & {$[-0.12,0.09]$} \\
\hline \multicolumn{6}{|c|}{ Model 1: $F(2,1083)=.09, p=.908 . R^{2}<.001$. Adjusted $R^{2}=0$} \\
\hline \multirow{11}{*}{ Model 2} & Intercept & $2.59(0.14)$ & 19.01 & $<.001$ & {$[2.32,2.86]$} \\
\hline & Condition & $-0.01(0.05)$ & -0.28 & .781 & {$[-0.12,0.09]$} \\
\hline & Male & $-0.04(0.06)$ & -0.77 & .441 & {$[-0.16,0.07]$} \\
\hline & Age & $<-0.01(<0.01)$ & -1.66 & .098 & {$[-0.01,<0.01]$} \\
\hline & White (vs. non-white) & $0.14(0.06)$ & 2.21 & .027 & {$[0.02,0.27]$} \\
\hline & ${ }^{\mathrm{a}}$ Education (Bachelors) & $-0.05(0.08)$ & -0.62 & .538 & {$[-0.20,0.11]$} \\
\hline & ${ }^{a}$ Education (Graduate Degree) & $0.10(0.09)$ & 1.08 & .280 & {$[-0.08,0.28]$} \\
\hline & $\begin{array}{l}\text { aEducation (Some College or } \\
\text { Associates) }\end{array}$ & $-0.03(0.07)$ & -0.48 & .634 & {$[-0.17,0.10]$} \\
\hline & Math Anxiety & $0.07(0.01)$ & 6.10 & $<.001$ & {$[0.05,0.09]$} \\
\hline & Percent Absolute Error & $-1.09(0.36)$ & -3.03 & .003 & {$[-1.80,-0.39]$} \\
\hline & Pretest Decision Making Accuracy & $0.09(0.06)$ & 1.57 & .117 & {$[-0.02,0.20]$} \\
\hline
\end{tabular}

Model 2: $F(10,1075)=5.52, \mathrm{p}<.001 . R^{2}=.049$. Adjust $R^{2}=.040$

Model 2 vs. $1: \Delta R^{2}=0.049, F(8,1075)=6.87, p<.001$.

Note: ${ }^{a}$ Each level of education is compared to participants who reported having a high school education or less. Condition was coded as $1=$ intervention and $0=$ control. 
Table A8. Linear regression effects on baseline perceived worry.

\begin{tabular}{|c|c|c|c|c|c|}
\hline & & $b(S E)$ & $t$ & $p$ & $95 \% \mathrm{CI}$ \\
\hline \multirow{3}{*}{ Model 1} & Intercept & $2.58(0.04)$ & 60.16 & $<.001$ & {$[2.49,2.66]$} \\
\hline & Condition & $0.06(0.05)$ & 1.27 & .204 & {$[-0.03,0.16]$} \\
\hline & Male & $-0.08(0.05)$ & -1.59 & .113 & {$[-0.18,0.02]$} \\
\hline \multicolumn{6}{|c|}{ Model 1: $F(2,1271)=2.19, p=.112, R^{2}=.003$. Adjusted $R^{2}=.002$} \\
\hline \multirow{11}{*}{ Model 2} & Intercept & $2.25(0.13)$ & 17.89 & $<.001$ & {$[2.00,2.50]$} \\
\hline & Condition & $0.06(0.05)$ & 1.23 & .220 & {$[-0.04,0.15]$} \\
\hline & Male & $-0.08(0.05)$ & -1.44 & .151 & {$[-0.18,0.03]$} \\
\hline & Age & $<-0.01(<0.01)$ & -1.86 & .063 & {$[-0.01,<0.01]$} \\
\hline & White (vs. non-white) & $0.08(0.06)$ & 1.47 & .143 & {$[-0.03,0.20]$} \\
\hline & ${ }^{\mathrm{a} E d u c a t i o n}$ (Bachelors) & $0.02(0.07)$ & 0.25 & .802 & {$[-0.12,0.16]$} \\
\hline & ${ }^{\mathrm{a} E d u c a t i o n}$ (Graduate Degree) & $0.13(0.09)$ & 1.48 & .138 & {$[-0.04,0.30]$} \\
\hline & $\begin{array}{l}\text { aEducation (Some College or } \\
\text { Associates) }\end{array}$ & $-0.03(0.06)$ & -0.49 & .627 & {$[-0.15,0.09]$} \\
\hline & Math Anxiety & $0.09(0.01)$ & 8.57 & $<.001$ & {$[0.07,0.11]$} \\
\hline & Percent Absolute Error & $-0.18(0.33)$ & -0.55 & .584 & {$[-0.83,0.47]$} \\
\hline & $\begin{array}{l}\text { Pretest Decision Making } \\
\text { Accuracy }\end{array}$ & $0.03(0.05)$ & 0.47 & .636 & {$[-0.08,0.13]$} \\
\hline
\end{tabular}

Model 2: $F(10,1263)=9.50, p<.001 . R^{2}=.070$. Adjust $R^{2}=.063$

Model 2 vs. $1: \Delta R^{2}=.067, F(8,1263)=11.29, p<.001$

Note: ${ }^{a}$ Each level of education is compared to participants who reported having a high school education or less. Condition was coded as $1=$ intervention and $0=$ control. 
Table A9. Linear regression effects on baseline positive affect.

\begin{tabular}{|c|c|c|c|c|c|}
\hline & & $b(S E)$ & $t$ & $p$ & $95 \% \mathrm{CI}$ \\
\hline & Intercept & $2.84(0.07)$ & 43.40 & $<.001$ & {$[2.71,2.97]$} \\
\hline Model 1 & Condition & $0.21(0.08)$ & 2.82 & .005 & {$[0.07,0.36]$} \\
\hline & Male & $0.27(0.08)$ & 3.57 & $<.001$ & {$[0.12,0.42]$} \\
\hline \multicolumn{6}{|c|}{ Model 1: $F(2,1287)=9.76, p<.001 . R^{2}=.015$. Adjusted $R^{2}=.013$} \\
\hline \multirow{11}{*}{ Model 2} & Intercept & $2.54(0.20)$ & 13.01 & $<.001$ & {$[2.16,2.92]$} \\
\hline & Condition & $0.21(0.08)$ & 2.76 & .006 & {$[0.06,0.35]$} \\
\hline & Male & $0.26(0.08)$ & 3.17 & .002 & {$[0.10,0.42]$} \\
\hline & Age & $<-0.01(<0.01)$ & -0.58 & .566 & {$[-0.01,<0.01]$} \\
\hline & White (vs. non-white) & $-0.24(0.09)$ & -2.66 & .008 & {$[-0.41,-0.06]$} \\
\hline & ${ }^{\mathrm{a} E d u c a t i o n}$ (Bachelors) & $0.30(0.11)$ & 2.71 & .007 & {$[0.08,0.52]$} \\
\hline & ${ }^{a}$ Education (Graduate Degree) & $0.35(0.14)$ & 2.57 & .010 & {$[0.08,0.61]$} \\
\hline & $\begin{array}{l}\text { aEducation (Some College or } \\
\text { Associates) }\end{array}$ & $0.22(0.09)$ & 2.30 & .022 & {$[0.03,0.40]$} \\
\hline & Math Anxiety & $-0.01(0.02)$ & -0.37 & .709 & {$[-0.04,0.03]$} \\
\hline & Percent Absolute Error & $2.41(0.51)$ & 4.71 & $<.001$ & {$[1.41,3.42]$} \\
\hline & Pretest Decision Making Accuracy & $-0.03(0.08)$ & -0.32 & .750 & {$[-0.19,0.14]$} \\
\hline
\end{tabular}

Model 2: $F(10,1279)=6.41, p<.001 . R^{2}=.048$, Adjusted $R^{2}=.040$

Model 2 vs. $1: \Delta R^{2}=0.033, F(8,1279)=5.50, p<.001$

Note: aEach level of education is compared to participants who reported having a high school education or less. Condition was coded as $1=$ intervention and $0=$ control. 
Table A10. Linear regression effects on baseline negative affect.

\begin{tabular}{llrrrr}
\hline & $\boldsymbol{b}(\boldsymbol{S E})$ & $\boldsymbol{t}$ & $\boldsymbol{p}$ & $\mathbf{9 5 \%} \mathbf{C I}$ \\
\hline Model 1 & Intercept & $2.90(0.08)$ & 37.82 & $<.001$ & {$[2.75,3.05]$} \\
& Male & $-0.03(0.09)$ & -0.38 & .703 & {$[-0.21,0.14]$} \\
Model 1: & $F(2,1287)=0.09, p=.918 . R^{2}<.001$. Adjust $R^{2}=0$ & & & \\
\hline Intercept & $0.01(0.09)$ & 0.14 & .892 & {$[-0.16,0.19]$} \\
Condition & $1.88(0.22)$ & 8.66 & $<.001$ & {$[1.45,2.30]$} \\
Male & $-0.03(0.08)$ & -0.39 & .693 & {$[-0.20,0.13]$} \\
Age & $0.10(0.09)$ & 1.10 & .272 & {$[-0.08,0.28]$} \\
White (vs. non-white) & $<-0.01(<0.01)$ & -0.93 & .354 & {$[-0.01,<0.01]$} \\
& a'Education (Bachelors) & $-0.02(0.10)$ & -0.18 & .856 & {$[-0.21,0.18]$} \\
Model 2 & $0.12(0.12)$ & 0.92 & .356 & {$[-0.13,0.36]$} \\
& aducation (Graduate Degree) & $0.08(0.15)$ & 0.55 & .583 & {$[-0.21,0.38]$} \\
& aEducation (Some College or & $0.07(0.10)$ & 0.63 & .530 & {$[-0.14,0.27]$} \\
Associates) & $0.23(0.02)$ & 13.01 & $<.001$ & {$[0.20,0.27]$} \\
Math Anxiety & $-0.30(0.57)$ & -0.53 & .594 & {$[-1.42,0.81]$} \\
Percent Absolute Error & $0.06(0.09)$ & 0.67 & .503 & {$[-0.12,0.24]$} \\
Pretest Decision Making & & & & \\
Accuracy &
\end{tabular}

Model 2: $F(10,1279)=19.25, p<.001 . R^{2}=.131$. Adjusted $R^{2}=.124$

Model 2 vs. $1: \Delta R^{2}=0.131, F(8,1279)=24.04, p<.001$

Note: aach level of education is compared to participants who reported having a high school education or less. Condition was coded as $1=$ intervention and $0=$ control. 


\section{Appendix B.}

Table B1. Effects of condition and covariates on risk perceptions measured across 10-day follow-up.

\begin{tabular}{llrrr}
\hline & $\boldsymbol{b}(\boldsymbol{S E})$ & $\boldsymbol{t}$ & $\boldsymbol{p}$ \\
\hline \multirow{2}{*}{ Model 1 } & Condercept & $5.15(0.15)$ & 33.82 & $<.001$ \\
& Day & $0.24(0.18)$ & 1.36 & .173 \\
Male & $0.05(0.01)$ & 6.06 & $<.001$ \\
& Intercept & $0.05(0.18)$ & 0.30 & .767 \\
Condition & $5.12(0.43)$ & 11.91 & $<.001$ \\
Day & $0.19(0.18)$ & 1.08 & .281 \\
Model 2 & Male & $0.05(0.01)$ & 6.08 & $<.001$ \\
& Age & $-0.06(0.19)$ & -0.31 & .758 \\
& White (vs. non-white) & $-0.02(0.01)$ & -2.71 & .007 \\
& aEducation (Bachelors) & $0.37(0.22)$ & 1.72 & .080 \\
& aEducation (Graduate Degree) & $-0.26(0.26)$ & -1.00 & .317 \\
aEducation (Some College or Associates) & $0.20(0.32)$ & 0.63 & .530 \\
Baseline Health Decision Making Accuracy & $0.17(0.23)$ & 0.72 & .470 \\
Percent Absolute Error & $-0.07(0.19)$ & 1.52 & .128 \\
Math Anxiety & $0.10(0.04)$ & 2.53 & .012 \\
\hline
\end{tabular}

Note: ${ }^{a}$ Each level of education is compared to participants who reported having a high school education or less. Condition was coded as $1=$ intervention and $0=$ control. 
Table B2. Effects of condition and covariates on perceived worry measured across 10-day follow-up.

\begin{tabular}{lrrr}
\hline & $\boldsymbol{b}(\boldsymbol{S E})$ & $\boldsymbol{t}$ & $\boldsymbol{p}$ \\
\hline \multirow{2}{*}{ Intercept } & $5.37(0.12)$ & 45.68 & $<.001$ \\
Codel 1 & $0.23(0.14)$ & 1.68 & .093 \\
Day & $0.001(0.01)$ & 0.16 & .876 \\
Male & $-0.28(0.14)$ & -2.05 & .041 \\
\hline Intercept & $5.28(0.33)$ & 15.84 & $<.001$ \\
Condition & $0.20(0.14)$ & 1.49 & .137 \\
Day & $0.001(0.01)$ & 0.17 & .867 \\
Male & $-0.20(0.15)$ & -1.31 & .192 \\
Age & $-0.01(0.004)$ & -1.88 & .061 \\
Model 2 White (vs. non-white) & $0.13(0.16)$ & 0.77 & .443 \\
${ }^{\text {a} E d u c a t i o n ~(B a c h e l o r s) ~}$ & $-0.18(0.20)$ & -0.92 & .358 \\
aEducation (Graduate Degree) & $0.02(0.25)$ & 0.07 & .944 \\
a'Education (Some College or Associates) & $-0.14(0.18)$ & -0.79 & .429 \\
Baseline Health Decision Making Accuracy & $-0.07(0.15)$ & -0.46 & .647 \\
Percent Absolute Error & $0.06(0.08)$ & 0.78 & .438 \\
Math Anxiety & $0.12(0.03)$ & 3.99 & $<.001$ \\
\hline
\end{tabular}

Note: ${ }^{a}$ Each level of education is compared to participants who reported having a high school education or less. Condition was coded as $1=$ intervention and $0=$ control. 
Table B3. Effects of condition and covariates on negative affect measured across 10-day followup.

\begin{tabular}{|c|c|c|c|c|}
\hline & & $b(S E)$ & $t$ & $p$ \\
\hline \multirow{4}{*}{ Model 1} & Intercept & $1.99(0.06)$ & 32.68 & $<.001$ \\
\hline & Condition & $0.01(0.07)$ & 0.11 & .909 \\
\hline & Day & $-0.01(.003)$ & -1.81 & .071 \\
\hline & Male & $-0.10(0.07)$ & -1.42 & .156 \\
\hline \multirow{12}{*}{ Model 2} & Intercept & $1.76(0.17)$ & 10.38 & $<.001$ \\
\hline & Condition & $-0.01(0.07)$ & -0.18 & .859 \\
\hline & Day & $-0.01(0.003)$ & -1.79 & .074 \\
\hline & Male & $-0.08(0.08)$ & -1.10 & .273 \\
\hline & Age & $-0.07(0.002)$ & -3.07 & .002 \\
\hline & White (vs. non-white) & $0.17(0.08)$ & 2.12 & .035 \\
\hline & ${ }^{\mathrm{a}}$ Education (Bachelors) & $-0.01(0.10)$ & -0.07 & .947 \\
\hline & aEducation (Graduate Degree) & $0.12(0.13)$ & 0.98 & .325 \\
\hline & ${ }^{\mathrm{a} E d u c a t i o n}$ (Some College or Associates) & $0.10(0.09)$ & 1.08 & .281 \\
\hline & Baseline Health Decision Making Accuracy & $0.01(0.08)$ & 0.22 & .828 \\
\hline & Percent Absolute Error & $0.02(0.04)$ & 0.50 & .619 \\
\hline & Math Anxiety & $0.09(0.02)$ & 5.75 & $<.001$ \\
\hline
\end{tabular}

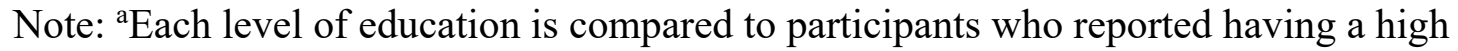
school education or less. Condition was coded as $1=$ intervention and $0=$ control. 
Table B4. Effects of condition and covariates on positive affect measured across 10-day followup.

\begin{tabular}{lrrr}
\hline & $\boldsymbol{b}(\boldsymbol{S E})$ & $\boldsymbol{t}$ & $\boldsymbol{p}$ \\
\hline Intercept & $2.18(0.05)$ & 40.77 & $<.001$ \\
Model 1 Condition & $0.09(0.06)$ & 1.51 & .131 \\
Day & $-0.02(0.003)$ & -5.17 & $<.001$ \\
Male & $0.18(0.06)$ & 2.77 & .006 \\
\hline Intercept & $2.27(0.15)$ & 14.80 & $<.001$ \\
Condition & $0.09(0.06)$ & 1.46 & .145 \\
Day & $-0.02(.003)$ & -5.20 & $<.001$ \\
Model 2 Male & $0.21(0.07)$ & 3.07 & .002 \\
Age & $0.002(0.002)$ & 0.74 & .461 \\
White (vs. non-white) & $-0.20(0.08)$ & -2.59 & .010 \\
a'Education (Bachelors) & $0.15(0.09)$ & 1.61 & 0.107 \\
aEducation (Graduate Degree) & $0.05(0.11)$ & 0.48 & .630 \\
aEducation (Some College or Associates) & $0.05(0.08)$ & 0.63 & 0.526 \\
Baseline Health Decision Making Accuracy & $-0.05(0.07)$ & -0.75 & .454 \\
Percent Absolute Error & $0.10(0.04)$ & 2.80 & .005 \\
Math Anxiety & $-0.02(0.01)$ & -1.15 & .252 \\
\hline
\end{tabular}

Note: ${ }^{\mathrm{a} E a c h}$ level of education is compared to participants who reported having a high school education or less. Condition was coded as $1=$ intervention and $0=$ control. 
Table B5. Effects of condition and covariates on CDC recommended health behaviors across 10day follow-up.

\begin{tabular}{|c|c|c|c|c|}
\hline & & $b(S E)$ & $t$ & $p$ \\
\hline \multirow{4}{*}{ Model 1} & Intercept & $7.11(0.14)$ & 49.06 & $<.001$ \\
\hline & Condition & $0.20(0.17)$ & 1.21 & .228 \\
\hline & Day & $-0.07(0.01)$ & -7.39 & $<.001$ \\
\hline & Male & $0.10(0.17)$ & 0.60 & .547 \\
\hline \multirow{8}{*}{ Model 2} & Intercept & $3.87(0.33)$ & 11.77 & $<.001$ \\
\hline & Condition & $0.15(0.15)$ & 0.96 & .339 \\
\hline & Day & $-0.06(0.01)$ & -6.77 & $<.001$ \\
\hline & Trait Negative Affect & $0.94(0.09)$ & 10.69 & $<.001$ \\
\hline & Trait Positive Affect & $0.66(0.10)$ & 6.70 & $<.001$ \\
\hline & State-Level Negative Affect & $0.27(0.06)$ & 4.30 & $<.001$ \\
\hline & State-Level Positive Affect & $0.18(0.06)$ & 3.20 & .002 \\
\hline & Male & $0.06(0.15)$ & 0.36 & .720 \\
\hline \multirow{16}{*}{ Model 3} & Intercept & $5.14(0.47)$ & 11.20 & $<.001$ \\
\hline & Condition & $0.10(0.15)$ & 0.70 & .486 \\
\hline & Day & $-0.06(0.01)$ & -6.82 & $<.001$ \\
\hline & Trait Negative Affect & $0.84(0.09)$ & 9.68 & $<.001$ \\
\hline & Trait Positive Affect & $0.53(0.10)$ & 5.51 & $<.001$ \\
\hline & State-Level Negative Affect & $0.27(0.06)$ & 4.30 & $<.001$ \\
\hline & State-Level Positive Affect & $0.18(0.06)$ & 3.27 & .001 \\
\hline & Male & $0.12(0.16)$ & 0.74 & .461 \\
\hline & Age & $-0.01(0.005)$ & -2.19 & .029 \\
\hline & White (vs. non-white) & $-0.62(0.18)$ & -3.49 & .001 \\
\hline & aEducation (Bachelors) & $0.53(0.21)$ & 2.50 & 0.01 \\
\hline & aaducation (Graduate Degree) & $0.69(0.27)$ & 2.61 & .009 \\
\hline & ${ }^{\text {aEducation (Some College or Associates) }}$ & $0.04(0.19)$ & 0.23 & .818 \\
\hline & Baseline Health Decision Making Accuracy & $-0.45(0.16)$ & -2.85 & .005 \\
\hline & Percent Absolute Error & $0.31(0.09)$ & 3.51 & $<.001$ \\
\hline & Math Anxiety & $0.04(0.03)$ & 1.24 & .215 \\
\hline
\end{tabular}

Note: ${ }^{a}$ Each level of education is compared to participants who reported having a high school education or less. Condition was coded as $1=$ intervention and $0=$ control. 
Table B6. Effect of condition and time on risk perceptions across time periods.

\begin{tabular}{clrrr}
\hline & $\boldsymbol{b}(\boldsymbol{S E})$ & $\boldsymbol{t}$ & $\boldsymbol{p}$ \\
\hline Time 1 & Condition & $0.15(0.19)$ & 0.79 & .428 \\
Male & $0.16(0.19)$ & 0.85 & .398 \\
Day & $0.18(0.04)$ & 4.36 & $<.001$ \\
\hline \multirow{2}{*}{ Time 2 } & & & \\
Intercept & $5.28(0.22)$ & 23.53 & $<.001$ \\
Male & $0.14(0.20)$ & 0.68 & .494 \\
Day & $0.01(0.03)$ & 0.41 & .681 \\
\hline & & & \\
Intercept & $5.30(0.22)$ & 23.72 & $<.001$ \\
Cime 3 & $0.39(0.20)$ & 1.96 & .051 \\
Male & $-0.02(0.21)$ & -0.11 & .913 \\
Day & $0.03(0.02)$ & 1.89 & .059 \\
\hline
\end{tabular}

Note: Condition was coded as $1=$ intervention and $0=$ control. 
Table B7. Effect of condition and time on perceived worry across time periods.

\begin{tabular}{|c|c|c|c|c|}
\hline & & $b(S E)$ & $t$ & \\
\hline & Intercept & $5.26(0.15)$ & 36.15 & $<.001$ \\
\hline \multirow[t]{4}{*}{ Time 1} & Condition & $0.43(0.18)$ & 2.40 & .017 \\
\hline & Male & $-0.17(0.15)$ & -1.17 & .242 \\
\hline & Day & $0.04(0.04)$ & 0.98 & .326 \\
\hline & Condition*Day & $-0.10(0.05)$ & -1.94 & .053 \\
\hline \multirow{4}{*}{ Time 2} & Intercept & $5.20(0.17)$ & 30.97 & $<.001$ \\
\hline & Condition & $0.23(0.15)$ & 1.54 & .125 \\
\hline & Male & $-0.27(0.15)$ & -1.80 & .073 \\
\hline & Day & $0.04(0.02)$ & 1.80 & .072 \\
\hline & Intercept & $5.48(0.17)$ & 33.19 & $<.001$ \\
\hline \multirow[t]{3}{*}{ Time 3} & Condition & $0.25(0.15)$ & 1.68 & .094 \\
\hline & Male & $-0.35(0.15)$ & -2.31 & .021 \\
\hline & Day & $-0.01(0.01)$ & -0.55 & .58 \\
\hline
\end{tabular}

Note: Condition was coded as $1=$ intervention and $0=$ control. 
Table B8. Effect of condition and time on positive affect across time periods.

\begin{tabular}{ccrrr}
\hline & $\boldsymbol{b}(\boldsymbol{S E})$ & $\boldsymbol{t}$ & $\boldsymbol{p}$ \\
\hline Intercept & $2.22(0.06)$ & 35.50 & $<.001$ \\
Time 1 Condition & $0.12(0.07)$ & 1.86 & .063 \\
Day & $-0.01(0.01)$ & -1.12 & .264 \\
Male & $0.11(0.07)$ & 1.64 & .102 \\
\hline Intercept & $2.21(0.08)$ & 26.41 & $<.001$ \\
Time 2 Condition & $0.07(0.07)$ & 1.04 & .300 \\
Day & $-0.03(0.01)$ & -2.08 & .038 \\
Male & $0.18(0.07)$ & 2.57 & .010 \\
\hline Intercept & $2.16(0.09)$ & 24.57 & $<.001$ \\
Time 3 Condition & $0.06(0.07)$ & 0.82 & .415 \\
Day & $-0.01(0.01)$ & -1.45 & .146 \\
Male & $0.19(0.07)$ & 2.59 & .010 \\
\hline
\end{tabular}

Note: Condition was coded as $1=$ intervention and $0=$ control. 


\section{Appendix C \\ Survey Flow}

Day 1: 40 minute session

\begin{tabular}{l}
\hline \\
\hline Baseline Measures \\
- Demographics \\
- Health decision-making \\
(Disease A vs. B) \\
- Perceived COVID-19 \\
knowledge \\
Emotion ratings \\
- Attitudes, anxiety, \\
numeracy, \& estimation
\end{tabular}

\section{Random Assignment to Intervention}

\section{Business-As-Usual}

- Participants presented with the \# of deaths (numerator) and total \# infected (denominator) for both the flu and COVID-19 in one table

WNB Intervention

- Preparatory activity using analogy

- Worked example for calculating fatality rate of COVID-19 vs. flu

- Visualization of rates
Health Decision-Making ImmediatePosttest \& Transfer

- Numerators \& denominators presented

- Decision accuracy \&

strategy choice measured
Post-Intervention Beliefs \& Attitudes about COVID-19

- Emotion ratings

- Risk perceptions

- Worry

- Need for cognition

- Health literacy 


\section{Appendix D \\ Exclusion Criteria}

Due to the nature of online sampling, we excluded participants who showed random or inattentive responding during the baseline survey and the daily diary. Of the 2,693 people who consented to participate, 832 were excluded for completing the survey in less than 13.33 minutes, or $1 / 3$ of the length of time (40 minutes) that it took research assistants to complete the survey on average during piloting. Of the remaining 1,861 participants, 305 were excluded for failing one of two attention checks (i.e., Select answer B; Gilman et al., 2017), and two were excluded for having completed the survey more than once. Thus, our pre-analytic sample included 1,554 people.

Additional pre-registered exclusion criteria were aimed at identifying "poor responders" on the baseline math tasks. For each number line estimation task (i.e., fractions, whole number frequencies, and percentages), a participant was flagged for exclusion if they had number line estimation precision (percent absolute error, see below) that had a standard deviation of .1 or less, or if $80 \%$ of their responses within a particular numerical range were above $95 \%$ or below $5 \%$ of the line (Fitzsimmons et al., in press; Sidney et al., 2019). That is, these participants had anchored their estimates at the endpoints of the number line and only placed their estimates within $10 \%$ of the number line on $80 \%$ or more of the trials. In the equivalence task, participants were flagged as poor responders for responding true or false to all items. Twenty participants were flagged as poor responders on two or more of these math tasks and excluded from analyses. Of the remaining 1,534 participants, we excluded eight participants who provided nonsensical answers to at least one of two open-ended items at the end of the study (e.g., "Is there anything else you would like to add regarding your thoughts about COVID-19?). We confirmed that these eight participants also provided nonsensical responses in their open-ended health decisionmaking strategy reports, suggesting they were not engaging with any of the open-ended items. Of these 1,526 participants, the 1,297 who answered all four forced-choice health decision-making questions comprised our analytic sample for the primary analyses.

Our analytic sample differed from those who consented to participate, yet were excluded, in terms of their age, $t(2680)=10.15, p<.001$, gender, $\mathrm{X}^{2}(1)=6.62, p=.01$, employment status, $X^{2}(6)=50.32, p<.001$, race/ethnicity (coded as: white vs. any other race), $X^{2}(1)=182.47, p<$ .0001 , reported income, $X^{2}(9)=71.06, p<.001$, number of math courses taken, $t(2633.5)=11.70$, $p<.001$, accuracy on an objective numeracy question (Berlin numeracy scale), $X^{2}(1)=95.44, p<$ .0001 , and accuracy on the baseline health decision-making problem, $X^{2}(1)=45.75, p<.0001$. That is, those who were excluded were more likely to be younger, female, students or selfemployed but less likely to be retired or employed for wages, be non-white, report lower income, have taken fewer math courses, and be incorrect on the objective numeracy and baseline health decision-making question. However, because our exclusion criteria aimed to identify non-human responding, these comparisons should be interpreted with caution.

Of the 1,297 participants from the baseline analytic sample, 709 participants completed the daily diaries over the next 10 days. 64 participants were excluded from the daily diary sample because they responded to signals less than 2 standard deviations below the sample mean $(M=$ $7.58, S D=3.11$, per convention (Bolger et al., 2003). Our analytic sample for the daily diary analyses was 627 because an additional 18 individuals failed embedded accuracy checks commonly used in online research (Gilman et al., 2017). The overall rate of compliance was 
acceptable, attrition was as expected and consistent with prior research and there were approximately 4,703 diary signals available for analysis (Bolger \& Laurenceau, 2013). 
Appendix E

Information Presented as Part of the Educational Intervention and Control Condition

\section{Educational Intervention}

Please take a look at the numbers in the table and read all of the information carefully. The goal of these examples is to help you better understand health statistics.

A farmer is trying to decide which types of apple trees to plant for next year. He is choosing between two types of trees, which are currently in two different fields. He wants to choose based on which type of tree is least likely to rot.

\begin{tabular}{|l|l|l|}
\hline & Number of rotting apple trees & Total number of apple trees \\
\hline Field A & 75 & 500 \\
\hline Field B & 25 & 100 \\
\hline
\end{tabular}

Looking at the table, it looks like more trees in Field A are rotting (75) than in Field B (25). But, notice that Field A also has many more total trees (500) than Field B (100). So, to decide which field has a higher rate of rotting trees, we cannot just compare the number of rotting trees in Field A to Field B. Instead, we must consider the number of rotten apple trees RELATIVE to the total number of trees in each field. You need to find the rotting RATE in each Field.

To find the rotting RATE, you divide the number of rotted trees by the total number of apple trees. So the rotting RATE in Field A is: $75 / 500=0.15$

Transform this into a percentage by multiplying by $100.0 .15 * 100=15 \%$. In other words, $15 \%$ of the trees planted in Field A have rotted.

The rotting RATE in Field B is: $25 / 100=0.25$.

Transform this into a percentage by multiplying by $100.0 .25 * 100=25 \%$. In other words, $25 \%$ of the trees planted in Field B have rotted.

If you compare the rotting RATE in Field A (15\%) to the rotting RATE in Field B (25\%), you can see that the rotting RATE is higher for Field B. Even though the number of rotting trees and total trees is greater in Field A, the rotting RATE is greater in Field B. 
Use what you just learned about the RATE of rotting trees to help you think about the fatality RATE of COVID-19.

The table below indicates the number of deaths as well as the total number of people infected by the flu and by COVID-19, as of March 19th, 2020. Note: Information was obtained from the Center for Systems Science and Engineering at Johns Hopkins website and the Center for Disease Control (CDC) website.

\begin{tabular}{|l|l|l|}
\hline & Number of deaths & Total number of people infected \\
\hline Flu & 22,000 & $36,000,000$ \\
\hline COVID-19 & 9,318 & 227,743 \\
\hline
\end{tabular}

In order to determine which disease is the most fatal, you must consider the number of deaths RELATIVE to the total number of people who were infected.

Here's a step-by-step tutorial on how you can figure out the fatality rate for each disease.

\section{First, find the Flu fatality RATE.}

Divide the number of Flu deaths $(22,000)$ by the total number of people infected by the Flu $(36,000,000)$. If you plug these numbers into a calculator, you will see that $22,000 / 36,000,000=$ 0.00061 .

Transform this into a percentage by multiplying by 100: $0.00061 * 100=.06 \%$. This is the fatality rate for the Flu. That's a pretty small number that is less than $1 \%$ and closer to $0 \%$ than to $5 \%$.

\begin{tabular}{|l|l|l|l|}
\hline & $\begin{array}{l}\text { Number of } \\
\text { deaths }\end{array}$ & $\begin{array}{l}\text { Total number of people } \\
\text { infected }\end{array}$ & Fatality Rate \\
\hline Flu & 22,000 & $36,000,000$ & $\begin{array}{l}\mathbf{2 2 , 0 0 0 / 3 6 , 0 0 0 , 0 0 0 = 0 . 0 0 0 6 1} \\
\mathbf{0 . 0 6} \%\end{array}$ \\
\hline COVID-19 & 9,318 & 227,743 & \\
\hline
\end{tabular}




\section{Second, find the COVID-19 fatality RATE.}

Divide the number of COVID-19 deaths $(9,318)$ by the total number of people infected by COVID-19 (227,743). If you plug these numbers into a calculator, you will see that 9,318 $/ 227,743=0.041$.

Transform this into a percentage by multiplying by $100: 0.041 * 100=4.1 \%$. This is the fatality rate for COVID-19. That's a bigger number that is closer to $5 \%$ than to $0 \%$.

\begin{tabular}{|l|l|l|l|}
\hline & $\begin{array}{l}\text { Number of } \\
\text { deaths }\end{array}$ & $\begin{array}{l}\text { Total number of people } \\
\text { infected }\end{array}$ & Fatality Rate \\
\hline Flu & 22,000 & $36,000,000$ & $22,000 / 36,000,000=0.00061=$ \\
$0.06 \%$
\end{tabular}

\begin{tabular}{|l|l|l|l|}
\hline & $\begin{array}{l}\text { Number of } \\
\text { deaths }\end{array}$ & $\begin{array}{l}\text { Total number of people } \\
\text { infected }\end{array}$ & Fatality Rate \\
\hline Flu & 22,000 & $36,000,000$ & $\begin{array}{l}22,000 / 36,000,000=0.00061= \\
0.06 \%\end{array}$ \\
\hline COVID-19 & 9,318 & 227,743 & $9,318 / 227,743=0.041=4.1 \%$ \\
\hline
\end{tabular}

Finally, compare the Flu's fatality rate $(0.06 \%)$ to COVID-19's fatality rate $(4.1 \%)$. You can see that the fatality rate is higher for COVID-19. In fact, as of March 19th, 2020 our best estimate is that it was 41 times more fatal.

One important thing to remember is that if you want to figure out a fatality rate, you have to take into consideration both the number of deaths as well as the total number of people infected for each disease.

Here is a graph to help you visualize the COVID-19 fatality rate (red in bottom bar) RELATIVE to the flu fatality rate (blue in top bar).

COVID-19

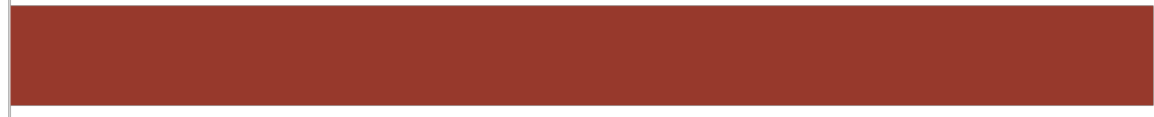




\section{Control Condition}

The table below indicates the number of deaths as well as the total number of people infected by the flu and by COVID-19, as of March 19th, 2020. Note: Information was obtained from the Center for Systems Science and Engineering at Johns Hopkins website and the Center for Disease Control (CDC) website.

\begin{tabular}{|l|l|l|}
\hline & Number of deaths & Total number of people infected \\
\hline Flu & 22,000 & $36,000,000$ \\
\hline Covid-19 & 9,318 & 227,743 \\
\hline
\end{tabular}




\section{Appendix F \\ Health Decision-Making Strategy Usage}

Strategy Report Coding Scheme with Definitions, Examples, and Proportion of Participants in Each Condition that Used Each Strategy for Each Health Decision-Making Item

\begin{tabular}{|c|c|c|c|c|}
\hline Code & Definition & Examples & $\begin{array}{l}\text { Prop. of } \\
\text { Control } \\
\text { Participa } \\
\text { nts Who } \\
\text { Used } \\
\text { Strategy }\end{array}$ & $\begin{array}{l}\text { Prop. of } \\
\text { Intervention } \\
\text { Participants } \\
\text { Who Used } \\
\text { Strategy }\end{array}$ \\
\hline $\begin{array}{l}\text { Larger } \\
\text { Numbers }\end{array}$ & $\begin{array}{l}\text { Indicated using } \\
\text { larger numbers } \\
\text { to guide decision } \\
\text { but doesn't } \\
\text { specify which } \\
\text { numbers } \\
\text { (numerator or } \\
\text { denominator). }\end{array}$ & 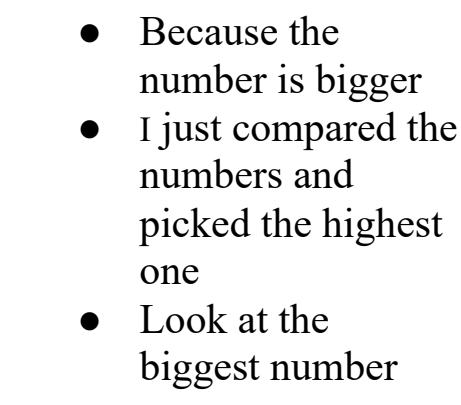 & $\begin{array}{l}\text { B: .04 } \\
\text { IP: } .03 \\
\text { NT: } .10 \\
\text { FT: .04 }\end{array}$ & $\begin{array}{l}\text { B: } .04 \\
\text { IP: } .02 \\
\text { NT: } .08 \\
\text { FT: } .04\end{array}$ \\
\hline Numerators & $\begin{array}{l}\text { Mentioned the } \\
\text { numerators (e.g., } \\
\text { number of } \\
\text { deaths) in } \\
\text { isolation when } \\
\text { comparing } \\
\text { diseases. }\end{array}$ & $\begin{array}{l}\text { - Most number dead } \\
\text { The number of } \\
\text { deaths from } \\
\text { Disease B is } \\
\text { significantly } \\
\text { higher than } \\
\text { Disease A. } \\
\text { - How many died } \\
\text { from it }\end{array}$ & $\begin{array}{l}\text { B: .23 } \\
\text { IP: } .16 \\
\text { NT: } .11 \\
\text { FT: } .07\end{array}$ & $\begin{array}{l}\text { B: } .24 \\
\text { IP: } .07 \\
\text { NT: } .10 \\
\text { FT: } .07\end{array}$ \\
\hline Denominators & $\begin{array}{l}\text { Mentioned the } \\
\text { denominators } \\
\text { (e.g., number of } \\
\text { people infected) } \\
\text { in isolation } \\
\text { when comparing } \\
\text { diseases. }\end{array}$ & $\begin{array}{l}\text { Disease B has } \\
\text { more people } \\
\text { infected } \\
\text { - More cases and so } \\
\text { on } \\
\text { - The population is } \\
\text { lower in Italy }\end{array}$ & $\begin{array}{l}\text { B: .14 } \\
\text { IP: } .08 \\
\text { NT: } .08 \\
\text { FT: } .13\end{array}$ & $\begin{array}{l}\text { B: } .15 \\
\text { IP: } .03 \\
\text { NT: } .06 \\
\text { FT: } .13\end{array}$ \\
\hline
\end{tabular}




\begin{tabular}{|c|c|c|c|c|}
\hline Rate & $\begin{array}{l}\text { Indicated } \\
\text { calculating a rate } \\
\text { or comparing } \\
\text { numbers, } \\
\text { including } \\
\text { transformations. }\end{array}$ & $\begin{array}{l}\text { - I divided the cases } \\
\text { into the deaths } \\
\text { They are close to } \\
\text { the same } \\
\text { percentage } \\
\text { - The second is } 1 \\
\text { per thousand } \\
\text { infected }\end{array}$ & $\begin{array}{l}\text { B: } .48 \\
\text { IP: } .47 \\
\text { NT: } .38 \\
\text { FT: } .41\end{array}$ & $\begin{array}{l}\text { B: } .50 \\
\text { IP: } .45 \\
\text { NT: } .42 \\
\text { FT: } .43\end{array}$ \\
\hline
\end{tabular}

\begin{tabular}{|c|c|c|c|c|}
\hline Math Error & $\begin{array}{l}\text { Indicated } \\
\text { calculating a rate } \\
\text { (e.g., by } \\
\text { dividing the } \\
\text { number of } \\
\text { deaths by the } \\
\text { number infected; } \\
\text { dividing the } \\
\text { number of } \\
\text { infected by the } \\
\text { total } \\
\text { population), but } \\
\text { made some type } \\
\text { of math error } \\
\text { (e.g., incorrect } \\
\text { rounding). }\end{array}$ & $\begin{array}{l}\text { I tried to divide the } \\
\text { number of people } \\
\text { who had the } \\
\text { disease by the } \\
\text { number of people } \\
\text { who died } \\
.056 \text { [instead of } \\
.0056 \text { for Far } \\
\text { Transfer] } \\
\text { Disease B is more } \\
\text { fatal because } 10 \% \\
\text { of the total \# of } \\
\text { infected } \\
\text { individuals died } \\
\text { [instead of } 1 \% \text { for } \\
\text { Baseline] }\end{array}$ & $\begin{array}{l}\text { B: } .04 \\
\text { IP: } .03 \\
\text { NT: } .02 \\
\text { FT: } .02\end{array}$ & $\begin{array}{l}\text { B: .07 } \\
\text { IP: .01 } \\
\text { NT: } .03 \\
\text { FT: } .03\end{array}$ \\
\hline
\end{tabular}

\begin{tabular}{|c|c|c|c|c|}
\hline $\begin{array}{l}\text { Ambiguous } \\
\text { Math }\end{array}$ & $\begin{array}{l}\text { Mentioned math } \\
\text { terminology or } \\
\text { some type of } \\
\text { calculation. If } \\
\text { the participant } \\
\text { indicated a rate } \\
\text { but was not } \\
\text { specific about } \\
\text { how it was } \\
\text { calculated, this } \\
\text { code was used } \\
\text { together with the } \\
\text { "rate" code } \\
\text { above. }\end{array}$ & $\begin{array}{l}\text { - According to the } \\
\text { statistics } \\
\text { - I did calculations } \\
\text { on both countries } \\
\text { - Using math }\end{array}$ & $\begin{array}{l}\text { B: } .34 \\
\text { IP: } .33 \\
\text { NT: } .37 \\
\text { FT: } .30\end{array}$ & $\begin{array}{l}\text { B: } .32 \\
\text { IP: } .39 \\
\text { NT: } .39 \\
\text { FT: } .33\end{array}$ \\
\hline
\end{tabular}




\begin{tabular}{|c|c|c|c|c|}
\hline $\begin{array}{l}\text { Condition- } \\
\text { Specific } \\
\text { Information }\end{array}$ & $\begin{array}{l}\text { Used } \\
\text { information } \\
\text { given in the } \\
\text { intervention } \\
\text { condition. }\end{array}$ & $\begin{array}{l}\text { - } \text { Rotting apples } \\
\text { compared to trees. } \\
\text { - You stated } \\
\text { COVID-19 was } 41 \\
\text { times more fatal } \\
\text { - It says on the } \\
\text { graph }\end{array}$ & $\begin{array}{l}\text { B: } .00 \\
\text { IP: } .00 \\
\text { NT: } .00 \\
\text { FT: } .00\end{array}$ & $\begin{array}{l}\text { B: } .00 \\
\text { IP: } .15 \\
\text { NT: } .02 \\
\text { FT: } .00\end{array}$ \\
\hline
\end{tabular}

\begin{tabular}{|c|c|c|c|c|}
\hline $\begin{array}{l}\text { News or } \\
\text { Media }\end{array}$ & $\begin{array}{l}\text { Mentioned } \\
\text { getting } \\
\text { information } \\
\text { from the } \\
\text { news/media or a } \\
\text { source other } \\
\text { than the } \\
\text { information } \\
\text { provided in this } \\
\text { study }\end{array}$ & $\begin{array}{l}\text { - What I heard on } \\
\text { the news reports } \\
\text { rather than the } \\
\text { above numbers } \\
\text { - United Nations } \\
\text { information } \\
\text { - According to } \\
\text { CNN, China has } \\
\text { got in control of } \\
\text { the spread of the } \\
\text { Coronavirus. }\end{array}$ & $\begin{array}{l}\text { B: } .00 \\
\text { IP: } .02 \\
\text { NT: } .03 \\
\text { FT: } .06\end{array}$ & $\begin{array}{l}\text { B: } .00 \\
\text { IP: } .02 \\
\text { NT: } .03 \\
\text { FT: } .06\end{array}$ \\
\hline
\end{tabular}

\begin{tabular}{|c|c|c|c|c|}
\hline $\begin{array}{l}\text { Personal } \\
\text { Beliefs or } \\
\text { Opinions }\end{array}$ & $\begin{array}{l}\text { Relied on } \\
\text { personal beliefs } \\
\text { or opinions, } \\
\text { including facts } \\
\text { (or myths) about } \\
\text { COVID-19 not } \\
\text { included in the } \\
\text { prompt. }\end{array}$ & 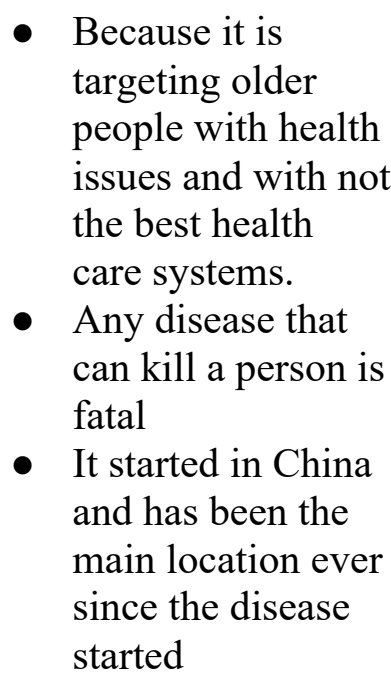 & $\begin{array}{l}\text { B: .09 } \\
\text { IP: } .13 \\
\text { NT: } .05 \\
\text { FT: } .06\end{array}$ & $\begin{array}{l}\text { B: } .07 \\
\text { IP: } .10 \\
\text { NT: } .05 \\
\text { FT: } .07\end{array}$ \\
\hline
\end{tabular}




\begin{tabular}{|c|c|c|c|c|}
\hline Other & $\begin{array}{l}\text { Mentioned } \\
\text { guessing; } \\
\text { provided a } \\
\text { response that } \\
\text { gave no insight } \\
\text { into reasoning; } \\
\text { mentioned } \\
\text { needing more } \\
\text { information to } \\
\text { decide. }\end{array}$ & $\begin{array}{l}\text { Process of } \\
\text { elimination } \\
\text { - Just do } \\
\text { - I can't determine } \\
\text { which is the } \\
\text { deadliest disease } \\
\text { with just the } \\
\text { information given }\end{array}$ & $\begin{array}{l}\text { B: .07 } \\
\text { IP: } .10 \\
\text { NT: } .13 \\
\text { FT: } .13\end{array}$ & $\begin{array}{l}\text { B: } .06 \\
\text { IP: } .10 \\
\text { NT: } .12 \\
\text { FT: } .12\end{array}$ \\
\hline
\end{tabular}

\begin{tabular}{|c|c|c|c|c|}
\hline Nonsense & $\begin{array}{l}\text { Responded with } \\
\text { strings of letters } \\
\text { or words that } \\
\text { were } \\
\text { nonsensical }\end{array}$ & $\begin{array}{l}\text { - } \text { Ddufiffm } \\
\text { good fo see real } \\
\text { there how volume } \\
\text { in how to earl }\end{array}$ & $\begin{array}{l}\text { B: .01 } \\
\text { IP: } .01 \\
\text { NT: } .02 \\
\text { FT: } .02\end{array}$ & $\begin{array}{l}\text { B: } .01 \\
\text { IP: } .02 \\
\text { NT: } .01 \\
\text { FT: } .02\end{array}$ \\
\hline
\end{tabular}

\begin{tabular}{llll}
\hline \multirow{2}{*}{ No Response } & Did not provide & B: .02 & B: .02 \\
& a response & IP: .02 & IP: .02 \\
& & NT: 03 & NT: 03 \\
& & FT .03 & FT: .03
\end{tabular}

Note: A response could receive more than one type of code. The first three codes (Larger Numbers, Numerators, Denominators) are considered to be consistent with Whole Number Bias (WNB). B = Baseline, IP = Immediate Posttest, NT = Near Transfer, and FT = Far Transfer. 


\section{Appendix G \\ Daily Diary Behaviors}

Please indicate whether you performed any of the following actions or behaviors in the past day:

Washed hands
regularly or used anti-
bacterial products
Purchased anti-
bacterial or cleaning
products
Looked for
information about
health or medical
topics from any
source
Looked for
information about
COVID-19 from any
source
Shared information
online or in-person
with others about
COVID-19
Spoke to or
contacted a medical
professional about
your health




\begin{tabular}{|c|c|c|c|}
\hline & No & Yes & Does Not Apply \\
\hline $\begin{array}{l}\text { Purchased extra food } \\
\text { for home }\end{array}$ & $\bigcirc$ & $\bigcirc$ & 0 \\
\hline $\begin{array}{l}\text { Used a surgical mask } \\
\text { to cover your face }\end{array}$ & 0 & 0 & 0 \\
\hline $\begin{array}{l}\text { Avoided public } \\
\text { transportation }\end{array}$ & 0 & 0 & 0 \\
\hline $\begin{array}{l}\text { Avoided contact with } \\
\text { people other than } \\
\text { those who live in your } \\
\text { household }\end{array}$ & $\bigcirc$ & 0 & 0 \\
\hline $\begin{array}{l}\text { Worked from home or } \\
\text { stayed home from } \\
\text { school }\end{array}$ & 0 & 0 & 0 \\
\hline $\begin{array}{l}\text { Covered your coughs } \\
\text { and sneezes } \\
\text { Avoided going to }\end{array}$ & $\bigcirc$ & 0 & 0 \\
\hline $\begin{array}{l}\text { public places, such } \\
\text { as bars or } \\
\text { restaurants }\end{array}$ & $\bigcirc$ & 0 & 0 \\
\hline
\end{tabular}

